\title{
The Cytology of Primula kewensis and of other related Primula Hybrids.
}

BY

\section{DIGBY.}

\section{With Plates XLI-XLIV and two Figures in the Text.}

$\Lambda^{\mathrm{T}}$ no time has the great problem of heredity, which involves such A far-reaching results, been more widely discussed or more diligently studied than at the present day. It is now realized that the possibility of an ultimate solution must entail the study of genetics combined with that of microscopical investigation, for it is within the cells that the factors reside which determine the morphological and physical character of the individual.

Much work has been done on the cytology of hybrids, both on the animal and on the vegetable side, and in many cases it has been possible to compare the nuclei of the parents with those of the offspring. The appearance and general character of the cytoplasm have been observed, the number and form of the chromosomes and their method of pairing in the bivalent combination have been described. After consideration of these cytological facts, conflicting hypotheses have been put forward in explanation of the causes of their frequently sterile condition. At present many of the detailed results remain as uncoordinated data, though it may be confidently anticipated that they will, in the future, be united into an intelligible scheme. It is in the hope of adding another item to these communications that this piece of work has been undertaken. Having regard to the curious horticultural history of the hybrid Primula kewensis, it seemed that a record of its cytology might be of interest. The attempt has been repaid, as the nuclear phases are wonderfully clear and the numbers of the chromosomes so low as practically to eliminate all chance of error. Moreover, the origin of the bivalent chromosome is suggestively easy of interpretation, and may throw some light on this much-vexed question.

\section{Methods.}

The buds have been capricious as regards fixation, and unless it has been good, the nuclei take the stain diffusely. In those cases where fixing and staining have been successful, nothing can exceed the clear definition of the nuclear phases. Sharpness of detail is characteristic of this series of Primulas.

[Annals of Botany, Vol. XXVI. No. CII. April, 1912.]

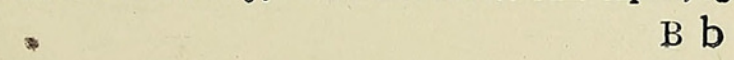


The buds have been fixed in strong Flemming, Hermann, alcohol and acetic, strong and medium chromo-acetic, and Merkel. Fixations have been made between II a.m. and I2.30 p.m. on bright warm days. Under these conditions plentiful nuclear divisions have been obtained.

It is found that the nuclei of many of the buds are in the state of rest which intervenes between the last premeiotic and the first meiotic division. This stage must be one of long duration, for during its period the whole bud grows considerably. There is again a resting stage during synapsis, for it is not unusual to find all the five anthers of a bud with their pollen mother-nuclei in close synapsis. From the coming out of synapsis to the completion of the homotype division the sequence of the nuclear phases is extraordinarily rapid. Often, in the microscope field of a transverse section of a bud, the nuclei of the youngest loculus will be in 'hollow spireme', whilst those of the oldest loculus will have already passed through the two meiotic divisions and be in the tetrad stage. The two outer loculi of an anther are always in advance of the inner two, and one loculus in each respective pair is slightly ahead of the other in the progress of nuclear division. Moreover, there is a great difference in the stages between the pollen mother-nuclei near the top of a given anther and those near the base of the same anther, so that by following the sequence of the sections of an anther cut transversely a perfect gradation can be obtained.

A variety of stains has been used, including Heidenhain's iron-alum haematoxylin with a counter stain; Flemming's triple; Breinl ; methylene blue and eosin ; gentian violet and orange G, \&c.

\section{HORTICUlTURAL History.}

It is well known that certain Primulas are not difficult to cross artificially, and occasionally accidental hybrids have arisen, and to this class belongs Primula kewensis (13 and 14). P. floribunda and P. verticillata were grown in quantities at Kew, and when in flower were constantly placed near to one another. In I $899 \mathrm{Mr}$. F. Garrett, the foreman, noticed in a pan of presumably pure $P$. floribunda seedlings one which was stronger in growth and different in foliage to the others. When it flowered it was evident that it was a hybrid, for it possessed the combined characters of $P$. floribunda and $P$. verticillata. It inherited from $P$. floribunda its continuous flowering nature, the colour of its flowers, and the shape of its leaves, and from $P$. verticillata its size, the length of its leaf-stalks, its foliaceous bracts, the character of its flowers, and the traces of mealiness on the corolla tube, on the upper part of the calyx, and on the leaves. The feature of mealiness is a most pronounced characteristic of $P$. verticillata. This hybrid plant, Primula kewensis (type form), was exhibited at the Meeting of the Royal Horticultural Society on February 27, 1900, and was awarded a First Class Certificate. 
During the summer of 1900 , in order to verify the supposition that $P$. floribunda and $P$. verticillata were in fact the parents of $P$. kewensis, the cross was successfully achieved artificially, using $P$. floribunda as the seed parent and $P$. verticillata as the pollen parent. A proportion of the resulting plants were true $P$. kewensis (29). The hybrid was sterile; all its flowers were thrum-eyed, and hence the stock could only be increased by cuttings or division.

In I9OI most of the sterile stock of $P$. kewensis passed into the hands of Messrs. Veitch and Sons of Chelsea. There it continued to bear only thrum-eyed flowers, until, about"1905, a single pin-eyed flower was noticed. This flower was fertilized with the pollen of a thrum-eyed flower and good seeds were set. These germinated, and the resultant plants bore both pin-eyed and thrum-eyed flowers and were fertile. Thus the whole presentday stock of the seedling or fertile $P$. kewensis has originated from the single pin-eyed flower on the type or sterile $P$. kervensis. Messrs. Veitch have since produced by selection, not by cross-breeding, a varietal form, which they have named $P$. kewensis farinosa. This resembles the fertile $P$. kewensis, except that it possesses the pronounced mealiness of the leaves, calyx, and corolla so characteristic of $P$. verticillata.

The cross between $P$. floribunda and $P$. verticillata has again been repeated at Kew by $\mathrm{Mr}$. J. Coutts, the foreman, in I9Io (29), but this time the offspring resembles the seed parent $P$. floribunda, and not a single plant of $P$. kewensis has appeared. On the other hand, $P$. verticillata crossed with $P$. floribunda isabellina has given rise to plants resembling $P$. kewensis farinosa, and, as will be observed, the interest is further enhanced by the fact that the number of chromosomes in this hybrid coincides with that of the plants of $P$. kewensis farinosa which were obtained by selection from $P$. kewensis (seedling form).

Such is the horticultural history of $P$. kewensis. It is now necessary to compare the chromosome numbers in the various generations.

\section{Chromosome Numbers in the Primula Generations.}

Both parents, $P$. floribund $a$ and $P$. verticillata, have $I 8$ for their diploid and 9 for their haploid number of chromosomes. These numbers, as might be expected, are repeated in the hybrid $P$. kewensis (type).

The fertile (seedling) P.kewensis has, however, by some means doubled the number of chromosomes, and possesses 36 for its diploid and 18 for its haploid number. These numbers are also retained in the varietal form $P$. kewensis farinosa, and again reappear in the $P$. kewensis farinosa which has arisen at Kew (29) as the result of crossing $P$. verticillata with $P$. floribunda isabellina, the pale form of $P$. floribunda.

Material of the fertile $P$. kewensis has been obtained from several 
sources, and in every case the doubled number of chromosomes has been substantiated.

A similar example of the sudden duplication in the number of chromosomes has been found amongst the Oenothera mutants (31, 17, and 20). 0 . gigas, which is known to have originated from $O$. Lamarckiana, has I4 haploid chromosomes, whilst O. Lamarckiana has only 7 haploid chromosomes.

Another unlooked-for result has been obtained from crossing $P$. floribunda isabellina with $P$. kewensis (seedling form) (29). This cross resembles that of $P$. floribunda isabellina crossed with $P$. kewensis (type) in external characters as well as in the number of the chromosomes. Both hybrids have the typical $P$. floribunda number, 18 diploid and 9 haploid. In the case of $P$. floribunda isabellina $\times P$. kewensis (type) this result would be expected, but in the case of $P$. floribunda isabellina $\times P$. kewensis (seedling), where one parent has twice as many chromosomes as the other, there must have been some reducing process at work whereby the sum of $9 x+18 x=182 x$. An analogous reduction in the number of chromosomes in the hybrid, one of whose parents possesses a higher number than the other, occurs in the classical instance of Drosera obovata (33 and 34) and in a hybrid Oenothera.

According to Geerts (20), when O. lata with its 7 haploid chromosomes is crossed with $O$. gigas with its 14 haploid chromosomes, at the first meiotic division the 7 homologous chromosomes pair and the 7 superfluous chromosomes disintegrate. It may be that some such explanation may account for the elimination of the chromosomes in the Primula cross.

\section{Table of Primula Crosses with their Chromosome Numbers.}

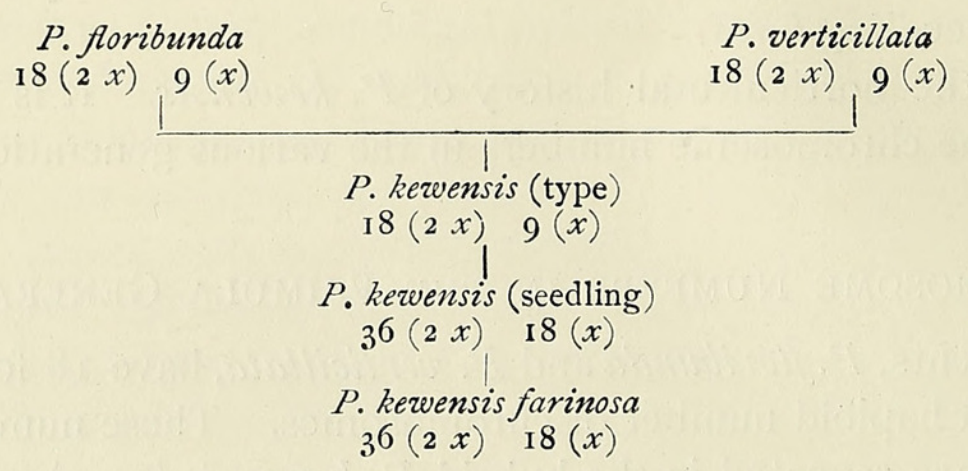

I9I0.

\footnotetext{
Seed Parent.

Pollen Parent.

RESUlT.

P. floribunda

P. floribunda isabellina

$P$. floribunda isabellina

$P$. verticillata

$P$. verticillata

$P$. kewensis (type)

Pollen Parent.
P. verticillata
P. kewensis (type)
P. kewensis (seedling)
P. floribunda
P. floribunda isabellina
P. Aloribunda isabellina

P. floribunda

P. floribunda isabellina

$P$. floribunda isabellina $P$. verticillata

$P$. kewensis farinosa

No seed.

Chromosomes.

$$
\begin{array}{ll}
\text { I } 8(2 x) & 9(x) \\
\text { I } 8(2 x) & 9(x) \\
\text { I } 8(2 x) & 9(x) \\
\text { I } 8(2 x) & 9(x) \\
\text { 36 (2x) } & \text { ? I } 8(x) 1
\end{array}
$$

1 The $(x)$ number of chromosomes has not been counted, the most advanced pollen mothernuclei being only in synapsis.
} 
My thanks are due to the authorities at Kew, through whose courtesy it has been possible to obtain buds of the original type form of $P$. kewensis, and of all the crosses made by the foreman, Mr. Coutts, during the year I9IO.

Messrs. Veitch have kindly supplied material from their stock of seedling $P$. kewensis and of $P$. kewensis farinosa.

It is proposed to begin the account of the cytology of this series of Primulas with a description of the premeiotic divisions. The seedling $P$. kewensis has been selected for this examination on account of the larger size of its nuclei as compared with those of the other forms. This will be followed by a review of the meiotic phase of the seed parent, $P$. floribunda. Subsequently that of the pollen parent, $P$. verticillata; of the sterile and of the fertile $P$. kewensis; of $P$. kewensis farinosa, and of the various crosses of I9IO will be dealt with in succession, but only the points of difference in the meiotic phase of these as compared with that of the selected type $P$. flor $i$ bunda will be noticed. Then it is proposed to consider briefly the mode of union of homologous lengths of spireme in the bivalent combination as exhibited in these Primulas, with regard to the 'parasynaptic' and 'telosynaptic' views. Finally, to survey the cytological work that has been done on hybrids, with special reference to the Oenotheras, which have so many features in common with the Primulas.

\section{Premeiotic Divisions.}

It has already been stated that there is a long rest between the premeiotic and meiotic divisions of these Primulas. Hence, unlike Galtonia (9) and other forms, where the one series of divisions passes imperceptibly into the other, in Primula there is no possibility of tracing the transition between the two. Primula therefore is not illuminating as regards the origin of the parallel threads and paired chromatin masses in the heterotype prophases.

In a telophase of one of the premeiotic or of the somatic divisions, no diagrammatic alveolization of the chromosomes is to be found, resulting in the formation of two parallel threads (9 and 21), phenomena which are so beautifully displayed by the nuclei of some plants. In the Primulas the substance of each entire chromosome breaks up, for the most part transversely, into rounded granular-like portions (Pl. XLI, Fig. I). Thus these granules are bits of whole somatic chromosomes, not bits of the longitudinal halves of somatic chromosomes. In Primula the granules may fragment into smaller and smaller particles, but in this fragmentation it would of course be impossible to say whether the division were longitudinal or transverse. In a late telophase the nucleus is traversed by a very fine arrangement of threads, and on these threads chromatin granules of various sizes are carried (Fig. 2).

When the nucleus enters upon the prophase, the granules trend 
together like beads on a string (Fig. 3). At first they take the stain lightly, but as they increase in volume and in definity they become more and more chromatic. Gradually the limits of the beaded individual chromosomes become discernible, and fine threads are seen connecting the beads of one chromosome to those of another (Fig. 4). Then the beaded appearance becomes less and less marked, until finally it blends into the homogeneous chromosome with a smooth outline (Figs. 5 and 6 ). The chromosomes go on to the spindle, and the neat compact equatorial plates are most characteristic. It is only when on the equatorial plate that the longitudinal fission in the substance of each chromosome becomes discernible.

Thus the different manner in which the formation of the mature somatic chromosome is accomplished in the Primulas as compared with

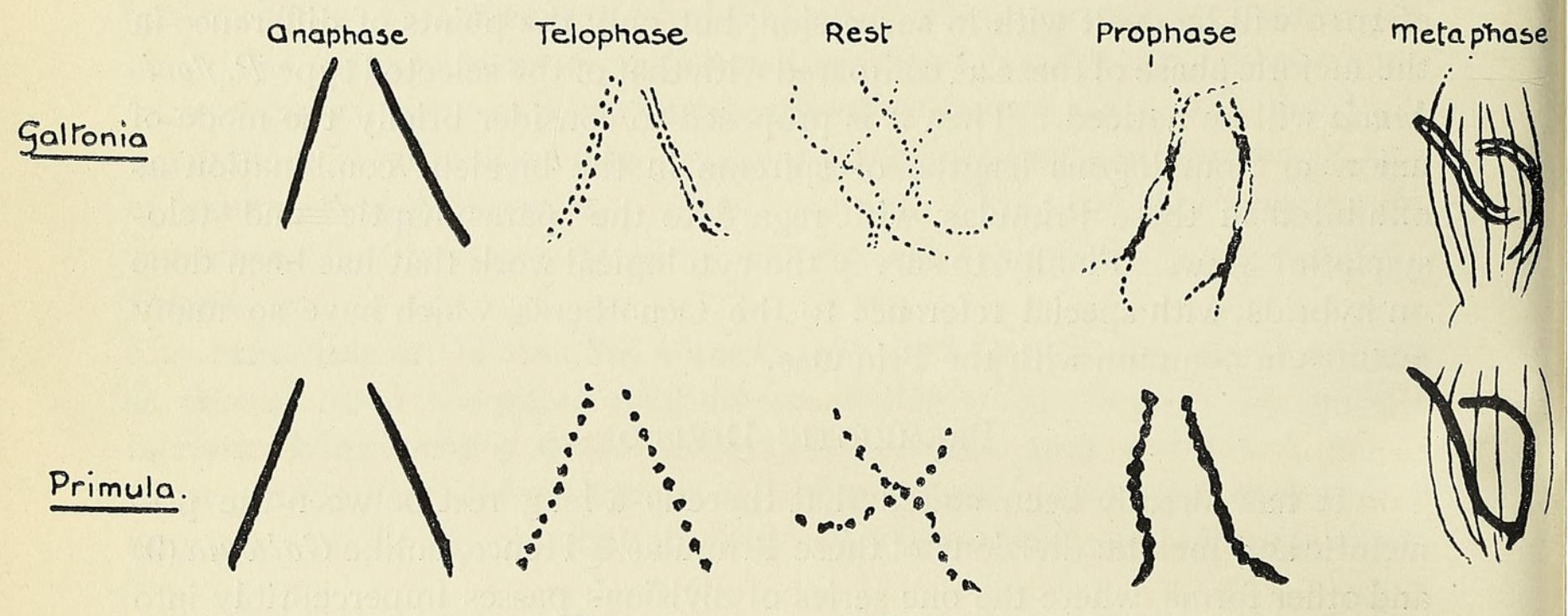

TEXT-FIG. I. Somatic division.

such forms as Allium (21), Galtonia (9), \&c., is simply due to the fact that in the Primulas the longitudinal halves of the portions of segmenting chromosomes during telophase tend to remain together, whereas in Allium, \&c., the longitudinal halves of the portions of segmenting chromosomes during telophase tend to separate (Text-fig. I). In this latter case the separation of the two halves results in two parallel threads, each of which is a portion of the longitudinal half of a somatic chromosome. During the ensuing prophase these longitudinal halves come together again to form the whole somatic chromosome, but often this union is incomplete, leaving a space (longitudinal fission) between the halves which will take effect and separate the two daughter chromosomes when they are arranged on the equatorial plate. On the other hand, in the Primulas, the homogeneous, unsplit chromosome of the telophase breaks across transversely into portions, which therefore represent pieces of whole somatic chromosomes. During the ensuing prophase these whole pieces come together end to end, 
remaining homogeneous, and do not display any inherent longitudinal fission until the chromosomes are about to proceed to the poles.

This tendency of the longitudinal halves of the univalent chromosomes to adhere to one another is also characteristic of the heterotype divisions, for in the early hollow spireme stage the univalent strands are homogeneous, and it is scarcely ever possible to detect any longitudinal fission in their substance.

During the somatic prophases the nucleolus buds constantly. This budding is carried on to a still greater extent during the heterotype prophase.

\section{Meiotic Phase of P. Floribunda.}

There is a long-drawn-out rest between the last premeiotic and the prophase of the first meiotic division. At the last premeiotic telophase the whole chromosome breaks up transversely into rounded portions (Fig. I). During the rest, these granules for the most part disappear; perhaps they are absorbed by the large nucleolus. The nucleolus occupies the centre of the nucleus and usually stains very deeply, but sometimes appears as a plasmosome. The nucleolus, whether it be chromatic or not in staining reaction, buds freely (Figs. 7 and 8). Apparently it acts as the store-house for chromatin, which it deburses by exuding droplets of its substance into the nuclear cavity. The small buds whilst still attached to the nucleolus are more faintly staining, but as they separate they become chromatic and take a very bright stain, and pass to the periphery of the nucleus. Very delicate connexions join these round chromatic bodies to one another and individual bodies to the nucleolus. When the bodies arrive at the periphery they break up into smaller granules which as a rule stain less brightly. These bodies might be considered as representing prochromosomes, but without doubt they are derived from the nucleolus, and they are irregular in size, in number, and in shape. The cytoplasm round the nucleus, at this stage, is very dense.

A precisely similar resting stage has been described by Gates (15) and by Davis (5) in the Oenotheras.

As the nucleolus continues to bud, the chromatin in the nucleus shows a decided increase, and this is accompanied by growth of the nucleus (Fig. 9), which may be said now to have entered upon the prophase. At the same time the fine connexions form more definite strands (Fig. IO), and the rounded beads of chromatin arrange themselves on the threads (Fig. I I). Sometimes several beads amalgamate to form an irregular mass, the earliest indication of the preparation for the coming synapsis (Fig. I2). In places the linin threads, bearing the chromatin beads, are seen to run parallel to one another and sometimes to join (Figs. IO, II, I2).

It is impossible to determine the significance of the parallel threads 
present in the heterotype prophase, owing to the undecipherable character of the nuclear phases that immediately precede and succeed it. During the rest which intervenes between the telophase of the last archesporial division and the prophase of the heterotype, the chromosomes resolve themselves so completely that all trace of their identity is lost to view, and the arrangement of their units passes beyond the limit of interpretation. Again, during synapsis, the course of events is completely veiled by the dense tangle of the spireme. The parallel threads may either represent the pairing of whole univalent lengths of chromosome, according to Grégoire's view (22), and in that case each thread would be homologous with a length of univalent beaded spireme of the premeiotic prophases, or they may represent the coming together of the halves of univalent lengths of chromosomes preparatory to the condensation for the whole somatic (univalent) chromosome. In Galtonia the homology between the parallel threads of the last premeiotic division (the result of the alveolization of each chromosome) and the parallel threads of the heterotype prophase can be traced through a continuous and progressive series. In both nuclear phases the parallel threads represent the longitudinal halves of the univalent chromosomes. During the telophase the process of the breaking up of the chromosomes and the distribution of their substance throughout the nucleus entail a separation of the longitudinal halves, whilst during the prophase the gradual evolution of the chromosomes involves an approach and an increasingly closer association of the longitudinal halves. It is believed that the same interpretation of the parallelisms found in the heterotype prophases may hold good for Primula, but for the reasons already given the surmise cannot be directly verified. Moreover, in Primula, as in other forms, it seems probable that the considerable thickening of strands may be due to the premature pairing of whole univalent chromosomes, a pairing which, in $P$. floribunda, is most clearly shown in the post-synaptic stages. When it is remembered that the completion of a mature bivalent chromosome entails not only the condensation of the two split halves of each univalent chromosome, but also the union of the two univalent chromosomes to form one bivalent combination, it does not seem irrational to believe that preparations for both may be proceeding simultaneously in the presynaptic stages.

The chromatic contents of the nucleus increase and concentrate into groups (Fig. I3), and diffuse throughout the linin. Gradually the whole masses together at one side of the nucleus. Parallelisms in the escaping portions can often be seen; and faint strands of linin may extend to the periphery of the nucleus as loops, or apparently as free ends. At complete synapsis the chromatin mass has a very granular appearance, and is contracted into an extremely small space (Fig. I4). Primula does not conform to Lawson's view (30) that there is no chromatin contraction during synapsis. The nucleolus is generally to be seen projecting from the synaptic knot, and 
is for the most part cytoplasmic in staining reaction, and once more buds freely. Droplets of nucleolar material may adhere to the chromatic knot (Fig. I4). Such droplets have been recently figured by Tischler (40) in Musa sapientum, var. Kladi, and he suggests that they may be of an excretory nature. They were also frequently seen in the synaptic figures of Galtonia (8 and 9).

As the synaptic knot unravels it loses its granular appearance and becomes more thread-like (Fig. I5). Occasional rounded chromatin masses are associated with the more definite lengths of spireme, and globules of faintly staining nucleolar material may be suspended with the chromatic substance (Fig. I5). The nucleolus is often pushed out first, and lies caught up by the loops in the clear space of the nuclear cavity. The appearances displayed by the loosening spireme are very various. For the most part it emerges in the form of loops, which stain homogeneously and show no longitudinal fission in their substance (Fig. I7). The looped spireme which comes out of synapsis and constitutes the familiar 'open spireme' stage is (for the most part) univalent in nature. It is, therefore, homologous with the univalent spireme of the somatic prophases. In the somatic prophases the univalent spireme segments directly into the independent univalent chromosomes; in the heterotype prophases, subsequent to the 'open spireme' stage, a pairing of univalent lengths of spireme takes place, resulting in a temporary association of two univalent chromosomes, forming the typical bivalent heterotype chromosome. Sometimes lengths of thick spireme, with bifurcating ends, emerge (Fig. I6). In some cases it seems obvious that the univalent lengths of spireme have already joined side by side-have, in fact, completed the approximation sometimes prepared for in the heterotype prophase. Especially in superficial sections of loosening knots, parallel threads arranged in a ladder-like way, united by bands of chromatin, are constantly to be found (Fig. I8). Notwithstanding the fact that some of the spireme, as it emerges from synapsis, may be bivalent in nature, yet the greater part is univalent, and it is only later that the definite arrangement of the individual univalent lengths into pairs to form the bivalent combinations takes place. Thus it seems probable that the rearrangement during synapsis has been chiefly concerned in the formation of the univalent lengths of spireme, and has not participated to any great extent in the pairing of the homologous univalent lengths of spireme. The looped nature of the spireme becomes more and more accentuated, and the already approximated portions tend to separate and to open out (Fig. I9). At the places of anastomosis there is always a chromatic swelling (Figs. I9 and 20).

During this time the nucleolus continues to bud freely. The buds become chromatic, and for a time remain tangled in the spireme. Sometimes more than one nucleolus is present.

At this and subsequent stages the nucleolus may stain either cyto- 
plasmically or chromatically; its reaction does not depend on the fixative, for contrary results may be obtained in buds killed in the same manner.

When the coming out of synapsis is completed, and the nucleus has returned to the centre of the cytoplasm, the beautiful looping of the continuous spireme is most striking (Fig. 20); by this time the chromatic aggregations have been absorbed. Although there is always a certain amount of anastamosis, it is often possible to focus the loops passing freely and separately within and without one another. If the spireme be both continuous and univalent, then the future univalent chromosomes must necessarily be arranged end to end in the spireme. This supposition is supported by subsequent phenomena leading to the realization of the heterotype chromosomes. The loops show no longitudinal fission in their substance; they are homogeneous, smooth surfaced, and faintly staining. The earliest indication of the association in pairs of homologous lengths of univalent spireme is the withdrawal of the spireme from the periphery of the nucleus, which at the same time becomes arranged in fewer and more distinct loops (Fig. 2 I).

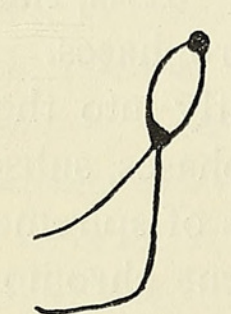

Univalent lengths of
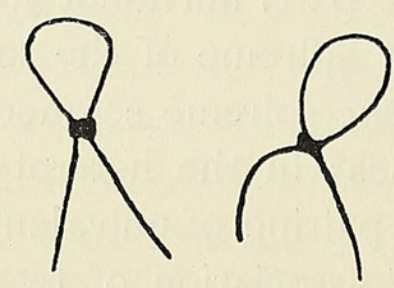

spireme joining
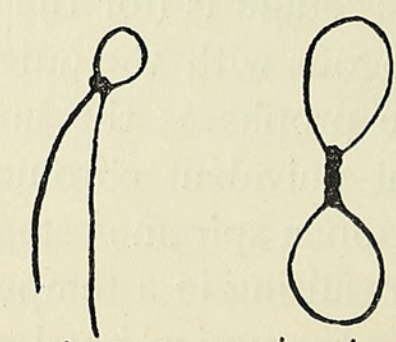

to form the bivalent combinations

TEXT-FIG. 2 .

The sides of the loops tend to approach one another and finally to join in places (Fig. 22). At the points of union there is always a chromatic swelling (Figs. 22 and 23). Sometimes the two sides of the same loop approximate, sometimes it appears as if the side of one loop crossed over and associated itself with the side of another. The nipping in of the loops at the places of contact and the otherwise somewhat wide divergence of their sides produce a variety of figures as shown in the diagram (Text-fig. 2).

This is the beginning of the union of univalent strands to form bivalent combinations. As will be shown, each side of one of these loops becomes eventually a univalent chromosome. By degrees the sides of the loops come to lie closer together, and are concentrated into more definite figures ( $F$ ig. 24). Then each bivalent combination, the future heterotype chromosome, begins to dissociate itself from its fellows, and for the first time free ends are to be seen (Fig. 24). A still closer approximation of the univalent sides continues, forming thick bivalent strands (Fig. 25). Sometimes this approximation takes the form of a ladder-like union (Fig. 24), as was described in the loosening of the synaptic knot (Fig. I8). There is a great variety, even in a single nucleus (Fig. 26), in the appearance of the chromatic segments at 
this stage, owing to the degree of progress exhibited in the process of the combination of the univalent strands. Some of the thick bivalent portions may open out into univalent loops ; in others, the sides of the loops may be still apart and only united at intervals, whilst in others the loop may be curved like a ring, the future ring-shaped chromosome. Although, perhaps, in some cases the univalent homologous segments of a bivalent combination may never be intimately joined together, yet, as a rule, at this stage, most of the univalent segments are united side by side in pairs forming thick strands (Figs. 26 and 27), which always reveal their double character.

There is no definite second contraction in $P$. floribunda; it seems to be represented by the close approximation of univalent segments in each separate bivalent combination (Figs. 26 and 27). This fact materially simplifies the difficulties as regards the evolution of the bivalent chromosome, for so frequently the massing of the segments in the second contraction hides the sequence of events. In $P$. floribunda it is often possible to identify the limits of the nine bivalent chromosomes (Fig. 27) at this stage.

Having accomplished the necessary lateral approximation, the two univalent sides then proceed to split apart (Fig. 28). At first this splitting may be restricted to certain lengths, leaving places where the two are still in contact (Figs. 28, 29, and 30), thus repeating the figures of their first association, but very rapidly the splitting extends until the two univalent chromosomes are only attached at one end, or at both ends when a ringshaped chromosome results (Fig. 3I). At the place where the two chromosomes are in contact there is constantly a chromatic swelling (Fig. 3I) like that which has been described at the points of union of the loops of the spireme. As the split separates the chromosomes, the chromatin of each becomes concentrated (Fig. 3I).

The sides of the bivalent chromosomes thicken considerably and their staining power intensifies. They are typical and beautifully shaped heterotype chromosomes, and there are usually three or four rings amongst them. Radiations from four centres appear in the cytoplasm (Fig. 32), and these extend to the nucleus, which by this time has lost its limiting membrane. Sometimes the four apices of the spindle can be detected in the microscopic field. The quadripolar spindle may persist for some time, but eventually it becomes bipolar. The chromosomes, which by this time have considerably contracted, attach themselves to the spindle. The spindle tapers to a point at either end and the fibres are coarse and distinct. Sometimes, in badly fixed material, where there has been much contraction, the spindle remains entire, showing that it is of so tough a consistency as to be untouched by violent chemical influences. The rigid character of the spindle radiations has been described by Farmer $(10$, p. 475) in Fossombronia. Often a laggard chromosome caps one of the spindle poles (Fig. 33), and then, belated, joins the other chromosomes on the plate. The equatorial 
plate is very neat, the chromosomes, dumb-bell or kite shaped, being arranged in perfect symmetry. A transverse section of this stage shows the nine chromosomes (Fig. 34). Gregory (24) has found the reduced number of chromosomes in $P$. sinensis to be twelve.

The nucleolus disappears as the chromosomes go on to the spindle. The separation of the univalent chromosomes and their retreat to the poles, to which they are drawn by stout spindle fibres, is very clearly demonstrated. The chromosomes are round or oval in shape, they stain deeply, and show no sign of longitudinal fission (Pl. XLII, Fig. 35). Arrived at the poles, they at first, in the usual manner, mass together and lose their individuality. Then they separate, fine threads join the segments one to the other, a nucleolus makes its appearance, and the nucleus becomes bounded by a limiting membrane. Cytoplas mic connexions passthrough the cell walls and join diasters of adjacent cells to one another (Fig. $3^{6}$ ). These connexions may be observed at earlier stages, but they are the more striking at the diaster, when the cytoplasm, contracted from the cell-walls, is mainly collected round the spindle. The fact that these cytoplasmic strands pierce the cell-walls gives a possible explanation for the transit of the chromatin bodies from one cell to another (8). Gates (15) has figured similar protoplasmic connexions between the pollen mother-cells of Oenothera rubrinervis.

To return to the telophase. The stages leading from the heterotype to the homotype division are extremely quickly passed through, in fact sometimes the chromosomes appear at once to reconstitute themselves. The more or less homogeneous masses of chromatin, representing the individual chromosomes, split longitudinally (Fig. 37), their sides become beaded (Fig. $3^{8}$ ), and fine threads join the various portions to one another. The nearest approach to a resting stage that has been found is a nucleus containing the skeleton of each chromosome clearly outlined by granules, and amongst them some indeterminate groups of granules (Fig. $3^{8}$ ).

The prophases of the homotype are indistinguishable from the telophases of the heterotype division, and the only means of recognizing the one from the other is that, by the time that the chromosomes are reconstituting themselves, there is no trace left of the spindle fibres of the heterotype division. The chromosomes are re-formed by the concentration of the granules. They show complete longitudinal fission, the two halves being in the same relative position to one another as the limbs of a V or of an X (Fig. 39). The figures are markedly tetrad-like in character (Fig. 40). Sometimes the fully formed chromosomes are composed of concentrated chromatin, sometimes they are beaded. Spindle fibres appear, and the chromosomes attach themselves irregularly (Fig. 40), but they finally collect at the equator, where they form a neat circle of dyads (Fig. 4I). One spindle is generally at right angles to the other, but 
occasionally they may both lie in the same plane. In a transverse section of an equatorial plate of the homotype division, the chromosomes are seen to be arranged in a square of three (Fig. 4I). The spindles taper bluntly. As in the heterotype anaphase, the chromosomes, on arriving at the poles, form themselves into a compact mass, and then separate out once more, and a nuclear wall forms (Fig. 42). The chromosomes then proceed to break up into granules. In the resting tetrad nuclei these granules are scattered in the nucleus, and are joined together by fine connexions. The cytoplasm between the nuclei constricts, and each of the four nuclei, surrounded by its cytoplasm, becomes an independent cell. At the late telophase of the homotype division the protoplasmic threads perforating the cell-walls' and joining tetrad groups to one another may still persist. The pollen-grain is tetrahedral in shape.

\section{P. VERTICILlatA.}

$P$. verticillata is a stronger and larger form than $P$. floribunda; the pollen mother-nuclei in both plants are almost identical in size, but the pollen-grains of $P$. verticillata are considerably the larger of the two.

The resting, presynaptic, and synaptic stages are similar to those already described in P. floribunda. From the synaptic stages onward there is, however, a decided modification on the simple process adopted by $P$. floribunda in the formation of its bivalent chromosomes, a process which can be clearly followed throughout its course, and is not marked by the confusion of the second contraction. P. verticillata, on the other hand, has a well-marked second contraction from which the bivalent chromosomes emerge. This is but another example of a feature which these Primulas share with the Oenotheras. Gates found a well-marked second contraction in Oenothera rubrinervis (15), whilst Davis saw none in O. biennis (5).

During the early hollow spireme stage of the heterotype division, tracts of spireme trend together, forming a flat, deeply staining, bandlike chromatic mass (Fig. 43). From this mass strands pass to the periphery of the nucleus. These strands are irregular in their distribution, vary in thickness, and anastomose freely with one another. The usual chromatic swellings are found at the places of anastomosis. At a slightly later stage the chromatic mass has further increased in bulk and is lumpy and thick in appearance, and from it radiate a few irregular loops of spireme (Fig. 44). Gradually, though the central chromatic concentration remains undecipherable, the escaping portions of spireme are seen to have a more definite arrangement and significance (Fig. 45). These may be in the form of loops, the univalent sides united at the apex, where there is the familiar chromatic swelling; or free bivalent ends may project showing the intimate side by side union of univalents; or loops of univalent spireme may be seen, anastomosing freely, but showing no approximation of homologous lengths. It is difficult to get a good fixation of this stage. In these 
preparations there has always been a considerable amount of contraction which is displayed by the crinkled edges of the cytoplasm. Gradually, as the second contraction becomes sorted out, the protruding portions of spireme thicken considerably, and clearly show their bivalent nature. Sometimes in the same nucleus (Fig. 46) some of the chromosomes may be almost fully formed, whilst the outline of others may be but indicated by the union of univalent spireme lengths, recalling the figures in the realization of the bivalent segments in $P$. floribunda. As the bivalent chromosomes emerge from the second contraction, they are often in the shape of rings joined together like the links of a chain (Fig. 47). Several rings may go to form one bivalent chromosome, for a large loop of spireme may become constricted in one or more places, resulting in a spectacle-shaped or chain-like chromosome.

When the nine bivalent chromosomes have been evolved out of the confusion of the second contraction they tend to segregate into two groups, and often the chromosomes in these groups become so pressed together as to lose their visible individuality (Fig. 48). Sometimes the chromosomes split into their univalent halves after they have issued from the second contraction. In that case the usual deeply staining, unsplit portions can be sharply distinguished from the symmetrically arranged, lightly staining, newly split univalent halves (Fig. 50). Under favourable conditions, but very rarely, the longitudinal fission in the but lately split limb can be seen (Fig. 49). The univalent chromosomes remain attached at one end, condense, and thicken considerably, and adopt the typical heterotype form (Fig. 5I). There are always several large ring chromosomes. A transverse section of an equatorial plate shows the nine diagrammatic chromosomes (Fig. $5^{2}$ ). The spindle is at first quadripolar, then becomes bipolar, and the univalent chromosomes proceed to the poles in the normal way. At the late telophase of the first meiotic division, or the early prophase of the second meiotic division, the nine longitudinally split chromosomes are beautifully clear (Fig. 53).

There is nothing further to add about the homotype division. It has already been mentioned that the pollen-grains of $P$. verticillata are larger than those of $P$. floribunda.

\section{P. KEWENSIS (type).}

The stages prior to the coming out of synapsis are like those of $P$. floribunda and $P$. verticillata.

In the formation of the bivalent segments, $P$. kezvensis (type) adopts a method intermediate between the simple pairing of univalent strands characteristic of $P$. floribund $a$ and the well-marked second contraction of $P$. verticillata. Although $P$. kewensis has no definite second contraction, there are small, isolated, thickened, chromatic areas to be found, formed by the massing, in places, of severral univalent segments. 
$P$. kewensis (type) resembles $P$. verticillata in the tendency of the bivalent chromosomes, after their evolution, to segregate into two groups, and also in the formation of chains.

As the spireme comes out of synapsis, it is much looped, and these loops intersect one another; at the junction there is the usual chromatic swelling (Fig. 54). By the time that the nucleus has returned to the centre of the cell, portions of chromatin of one nucleus may be protruded into the adjoining cell, at the same time retaining a connexion with the mother nucleus (Fig. 55). This phenomenon has not been seen in the other species of Primula examined, and recalls a similar condition figured by Gregory (23) in the Sterile Pea. These chromatic protrusions when found in Primula are not nearly so striking as the 'bodies' which are thrown off in Galtonia (8), and moreover suggest possible nuclear degeneration.

After the univalent loops have arranged themselves throughout the nuclear cavity, the spireme is as a whole much more beaded in character than is that of either of the parents. The beaded lengths of spireme arrange themselves in squares and in parallel lines, and in some places they unite to form the bivalent combination (Fig. 56). A single nucleus may exhibit very varied contents, for the same nucleus may have portions of its spireme in the beaded condition, whilst other portions may be homogeneous and pair as in P. floribunda (Fig. 57). Where the rows of beads, or the lengths of strands come together, there is always a decided thickening. A ladder-like condensation of univalent spiremes is of very common occurrence (Fig. 58). Strands may coalesce in one or more places, and create an undecipherable mass which may be described as an attempt to form a second contraction (Fig. $5^{8}$ ).

In $P$. floribunda there is a stage when all, or nearly all, of the univalent segments are joined in their homologous pairs prior to the final splitting apart. On the other hand, in P. kewensis (sterile), some of the univalent lengths may be in the act of pairing, whilst others may already be splitting apart, and it is possible that in some cases a close union of the univalent members of each pair may never be achieved. Gates (15) has described the attraction for pairing between homologous chromosomes as being very weak in the mutant $O$. nubrinervis.

All stages in the splitting apart of the joined univalent segments may be seen (Fig. 59). These then concentrate and thicken, until the forms of the future bivalent chromosomes are recognizable (Fig. 60). When the bivalent chromosomes are individualized they tend, as in $P$. verticillata, to mass together into two groups (Fig. 6I). When they again distribute themselves throughout the nucleus chains of rings are constantly to be seen (Fig. 62), and, as in $P$. verticillata, it is evident that several rings go to form one bivalent chromosome. 
Then the univalent limbs of each bivalent chromosome diverge widely, and together they fill up the greater part of the nuclear cavity (Fig. 63). This is followed by a shortening and thickening of the chromosomes (Fig. 64), the spindle makes its appearance and the chromosomes attach themselves to the fibres (Fig. 66). A transverse section of an equatorial plate shows the typical nine chromosomes (Fig. 65).

There is nothing further to add about the heterotype division; this is followed by the homotype resulting in the formation of tetrads (PI. XLIII, Fig. 67). It is only when the tetrad nuclei begin to separate from one another that some of the cells atrophy. A relatively small proportion of the pollengrains appear to be normal (Fig. 68), but there are always depauperate ones amongst them (Fig. 69). Some of the anthers have a far higher percentage of healthy pollen-grains than have others.

In order to ascertain that apogamy is not responsible for the unaccountable doubling in the numbers of the chromosomes the embryo-sacs of both $P$. kewensis (sterile) and $P$. kewensis (fertile) have been examined. In both cases everthing is regular. In $P$. kewensis (sterile) I 8 chromosomes (Fig. 70) are found in the nuclei of the nucellus, and 9 in the nuclei of the embryo-sac mother-cell (Fig. 7I).

\section{P. kewensis (seedling form).}

The striking and all-prevailing difference between $P$. kewensis (fertile or seedling) and those Primulas to which it is related is the fact that it has doubled its chromosomes. By some means, probably at the act of fertilization of the single pin flower, by pollen of the thrum flower, borne on the sterile stock, the $4(x)$ number of chromosomes has been obtained, and this $4(x)$ number is characteristic of all its subsequent generations. Moreover, $P$. kewensis with the $4(x)$ number is fertile, whilst $P$. kewensis with the $2(x)$ number is sterile. $P$. kezwensis (fertile) has therefore $3^{6}$ diploid (Pl. XLI, Fig. 6) and I 8 haploid chromosomes (Pl. XLIII, Fig. 96). This double number is continued in the variety $P$. kewensis farinosa (P1. XLIV, Figs. 107 and 108).

A most interesting recurrence of the doubling of the chromosomes has reappeared in the Primula crosses made at Kew in I9IO (29). The result of $P$. verticillata crossed with $P$. floribunda isabellina is a hybrid, which not only resembles $P$. kewensis farinosa in its external characters, but also with regard to its nuclei, for it possesses the number of chromosomes characteristic of the fertile $P$. kewensis, namely $3^{6}(2 x)$ (Fig. 108) chromosomes, that is to say it has duplicated the parental number. Thus the variety $P$. kewensis farinosa has arisen as the direct result of a cross, and indirectly as the result of a cross which has passed through an intervening sterile period. In both cases the number of chromosomes has been doubled.

The phenomenon of the sudden duplication of a chromosome number 
has its parallel in the Oenotheras. The parent type, O. Lamarckiana, possesses I $4(2 x)$ and $7(x)$ chromosomes; its mutant, $O$. gigas, possesses $28(2 x)$ and $14(x)$ chromosomes. This fact was first observed by Lutz (31), who counted 28 or 29 chromosomes in the roots. The numbers I $4(2 x)$ and $7(x)$ seem to be characteristic of this series of Oenothera; they are found in $O$. lata, in $O$. nanella, in the mutant $O$. rubrinervis, and in the hybrid arising from the cross 0 . lata $\times$ O. Lamarckiana.

0 . gigas appeared first in de Vries's experimental garden in 1895 amongst a crop of $O$. Lamarckiana which was known to have bred true for three previous generations (7). It arose without any intermediate stage, and the plants, grown from self-fertilized seeds, were with one exception pure gigas. Thus a new elementary species can 'appear without any obvious cause in a single individual and be absolutely constant from the very first' $(7)$. O. gigas reappeared in 1898 from the seeds of a plant of 1). sublinearis, which had itself arisen from the Lamarckiana family; and again in 1899 from a cross between $O$. lata and $O$. hirtella. Thus, like $P$. kewensis (seedling form), O. gigas has originated from more than one source. Gates $(17)$ has worked out the cytology of the pollen mother-cells of $O$. gigas in detail, and he believes that the doubling of the chromosome number is to be regarded merely as a duplication of the set of chromosomes present in $O$. Lamarckiana. "There is no evidence that any new unit characters have been added, or that anything really new has come into the germ plasm.' Whereas in P. kewensis the acquirement of the double number of chromosomes is apparently associated with the change from a sterile to a fertile condition.

$P$. kewensis (fertile) makes no attempt to form a second contraction, and in that respect resembles its parent $P$. floribunda. Another cytological characteristic peculiar to $P$. kewensis (fertile) is the temporary joining together of two of the bivalent chromosomes in the first meiotic division, resulting in a large quadrivalent chromosome, an association which is maintained until the univalent chromosomes, after having collected at the equatorial plate, separate off to the poles of the spindle. Further, $P$. kewensis (fertile) has a remarkable diakinesis in which the chromosomes are much contracted, a stage which has never been seen in the other Primulas. Lastly, the nuclei of the pollen mother-cells of $P$. kewensis (seedling) are considerably larger than are those of its parents. Thus it affords another example of the size of the nucleus in relation to the number of its contained chromosomes.

A rest occurs between the last premeiotic and the first meiotic division as in the other Primulas. During this and the subsequent stages the nucleolus buds most vigorously (P1. XLIII, Fig. 72). There is a close synaptic knot, which leaves a large nuclear space. The buds at first stain faintly, but they gradually become chromatic in their staining reaction. 
As the spireme comes out of synapsis the nucleolus continues to bud, with the result that many large rounded chromatin masses are caught up in the loops of the spireme (Fig. 73). In course of time these seem to become absorbed (Fig. 74), for they disappear, leaving only a few isolated beads, which are generally situated at the points of intersection of the loops (Fig. 74). The somewhat beaded character of the spireme recalls that of the sterile $P$. kewensis (Fig. 75). The beads are joined together by fine threads, and these tend to run in pairs, and where they meet there is always a chromatic swelling (Fig. 75). Even at this early stage in the pairing of homologous univalent spireme lengths it is possible to distinguish the skeleton of the future bivalent chromosomes. Gradually the paired portions of univalent spireme severally dissociate themselves from the others. At first these parallel threads have paired chromatin masses arranged at intervals along their length (Fig. 75), but as concentration proceeds less and less of the thread is visible, the chromatin becoming more diffuse (Fig. 76); as the sides of the chromosomes concentrate they become beaded (Figs. 77 and 78 ).

When it is possible to identify the limits of the individual bivalent chromosomes, it is apparent that two are joined together end to end (Figs. 79 and 80), forming as a rule a large looped figure. The univalent sides of each bivalent chromosome thicken, and often one or two chromosomes remain attached to the nucleolus (Fig. 8I). Gradually the chromosomes become typically heterotype in shape (Fig. 82), and the large quadrivalent chromosome is most striking (Fig. 83). Then the heterotype chromosomes separate from one another, they become increasingly beaded (Fig. 84), and the fine threads joining them are tightly stretched. They stain less deeply and contract considerably (Figs. 85 and 86 ); the large chromosome often takes the shape of a ring (Fig. 86). After passing through this extremely beaded phase the chromosomes gradually lose their granular appearance and become slightly more condensed (Fig. 87), more homogeneous, and rounded in outline (Fig. 88). There is still further contraction of the chromosomes, each univalent chromosome of the bivalent combination becoming oval or rounded in shape (Fig. 89), the large chromosome appearing as a tetrad (Figs. 89, 90, and 9I). The tetrad may be in the form of a square, or of a closed or partially opened ring, but in every case its fourfold character is evident (Fig. 91). The bivalent chromosomes are placed widely apart, and they are still connected to one another by fine threads. The nucleolus has by this time fragmented, and rounded globules of faintly staining nucleolar material may be seen adhering to the chromosomes (Fig. 92). Such is the peculiar and characteristic diakinesis of $P$. kewensis (fertile), the preparation for which is so prolonged.

Several counts have been made of the chromosomes at this stage. Very rarely I 8 bivalent chromosomes all of the same size are to be found; 
the greater number show I 7 bivalent chromosomes together with I quadrivalent chromosome, a few show 16 bivalent and I quadrivalent, and one case was found of 15 bivalent and 2 quadrivalent. Some of the discrepancies may be accounted for by the fact that the nuclei appeared in two sections and had to be pieced together, but the trend of the results seem to prove conclusively that the large chromosome represents the joining together of two bivalent chromosomes, and this statement is further corroborated by the subsequent behaviour of the large chromosome on the equatorial plate.

It is irteresting to note that Rosenberg (33) in the hybrid Drosera obovata found that the chromosomes in the homotype division sometimes appeared as tetrads, and remarks 'dass wir in dem Vorkommen der Vierergruppen im zweiten Teilungsschritt einen Ausdruck der Hybridität sehen können' (p. II6).

Strasburger (35) in Melandrium rubrum describes one chromosome in the heterotype division which is much larger than the others; it reappears in the homotype division, and is present also in the embryo-sac mother-cell.

Agar (I) noted a conspicuously larger pair of chromosomes in Lepidosiren paradoxa, which are seen in the spermatogonial divisions, and which can be identified throughout the two maturation divisions.

In both Melandrium and Lepidosiren the large bivalent chromosome results from the association of two proportionately larger univalent chromosomes, and not from the temporary union of two bivalent chromosomes as in $P$. kewensis (fertile).

The spindle of $P$. kezvensis (fertile), like that of the other Primulas, is quadripolar at its origin (Fig. 93). When the chromosomes have completed their equatorial arrangement, the quadrivalent chromosome is easily recognized (Figs. 94 and 95). Sometimes before the other chromosomes have separated, the quadrivalent chromosome may have prematurely divided into its four univalent units, though the members of each pair may continue to be joined one to the other (Fig. 94); in other cases the quadrivalent chromosome may not divide until the other chromosomes are about to pass to the poles (Fig. 95). The chromosomes have been counted several times in the polar views of equatorial plates. In several cases the number has been found to be 18 (Fig. 96), but I 7, 16, I5, and even 14 chromosomes have been counted. Possibly this inaccuracy may be due to the position and relative degree of separation of the quadrivalent chromosome. 'This suggestion is supported by the fact that polar views of anaphases and polar views of asters (Pl. XLIV, Fig. 99) almost invariably show I 8 chromosomes.

As they proceed to the poles (Pl. XLIII, Fig. 97) the univalent chromosomes which composed the quadrivalent combination cannot be distinguished from the others (Pl. XLIV, Fig. 98). The anaphase and telophase have been studied in detail, and there is no reappearance of the large chromosome. The chromosomes of the late anaphase at first mass together (Fig. I00), then 
as they protrude and stretch to the periphery of the nucleus a limiting nuclear membrane appears(Fig. IOI); gradually each chromosome lies independently, as a rounded mass of homogeneous chromatin, in the nuclear cavity (Fig. I02). In a polar view of this stage 18 chromosomes have again been counted. A definite cloudy band, indicating the position of the future cell-wall, stretches across the equator of the fast disappearing spindle (Fig. I02). The next stage shows the longitudinal fission of the chromosomes preparatory for the homotype division (Fig. I03); again I 8 chromosomes can be counted. There is nothing remarkable about the homotype division; it is normal in every way.

The pollen-grains are larger than those of $P$. floribunda, and approximate in size to those of $P$. verticillata.

The embryo-sac has been examined, and the embryo-sac mother-cell nuclei show I 8 bivalent chromosomes (Fig. 106). There is no indication of the adherence of two bivalent chromosomes; apparently this peculiarity is only characteristic of the heterotype division of the pollen mother-nuclei. At diakinesis (Fig. 104), in the profile (Fig. 105), and in the polar (Fig. 106) views of equatorial plates all the bivalent chromosomes are of the same size and are independent of one another.

\section{P. kewensis farinosa.}

It has already been mentioned that $P$. kewensis farinosa has arisen from two sources: in the one case as a variety of the fertile $P$. kewensis, in the other as the direct result of a cross between $P$. verticillata and $P$. floribunda isabellina (29), and both have doubled the number of the parental chromosomes.

The meiotic phase of $P$. kewensis farinosa obtained by Messrs. Veitch from selection of $P$. kewensis (seedling) has only been studied with the view of ascertaining the number of the chromosomes, and these without any doubt are 36 and 18 (Fig. I07).

The buds procured from the $P$. kezvensis farinosa hybrid at Kew were young and had not as yet entered upon meiosis, but the somatic and archesporial divisions showed clearly that their chromosomes numbered $3^{6}$ (Fig. I08).

Therefore 0 . gigas, whether it arises as a mutant or as a hybrid, and $P$. kewensis farinosa, whether it arises indirectly or directly as a hybrid, have both in each case doubled the parental number of chromosomes.

\section{P. verticillata $\times$ P. floribunda.}

The result of the cross between $P$. verticillata and $P$. floribunda (29) is a hybrid which repeats the number of the parental chromosomes, I $8(2 x)$ and $g(x)$, and resembles the seed parent, $P$. verticillata. 


\section{P. floribunda isabellina $\times$ P. kewensis (type).}

The hybrid derived from this cross resembles the seed parent, $P$. floribunda isabellina, and possesses the I $8(2, x)$ and $9(x)$ chromosomes.

The reciprocal cross, $P$. kewensis (type) $\times P$. floribunda isabellina, set no good seed.

\section{P. floribunda isabellina $\times$ P. kewensis (seedling form).}

An unexpected result is obtained from this cross. The hybrid resembles that of the preceding cross, $P$. floribunda isabellina crossed with the sterile $P$. kewensis, in external features as well as in the number of chromosomes, which are accordingly i $8(2 x)$ and $9(x)$, notwithstanding the fact that one of the parents possesses the doubled number, $3^{6}(2 x)$ and I $8(x)$.

It is difficult to imagine by what regulating process this reduction in the number of chromosomes has been achieved; that is to say, how $18(x)$ uniting with $9(x)$ can give the result of I $8(2 x)$. Once more the Oenotheras show an analogy, and offer a possible explanation for this phenomenon. $O$. lata, which has $\mathrm{I} 4(2 x)$ and $7(x)$ chromosomes, crossed with $O$. gigas, which has $28(2 x)$ and $14(x)$ chromosomes, gives rise to a hybrid which has 2 I $(2 x)$ chromosomes. In the heterotype prophase the chromosomes appear unpaired in their $2 x$ numbers. Subsequently, as in the Drosera hybrid (34), Geerts (20) finds that the homologous chromosomes derived from either parent pair with one another and that the supernumerary chromosomes remain unpaired. In the Oenothera hybrid, therefore, $7 \mathrm{bi}$ valent and 7 univalent chromosomes go on to the spindle. The 7 bivalent chromosomes separate normally, whilst the 7 univalent ones disintegrate. Some of the fragments may eventually reach the poles, but many may be left on the spindle and never enter the reconstructing nuclei. Geerts obtains the same results in the hybrid resulting from the cross between $O$.gigas and $O$. Lamarckiana and in the reciprocal cross of $O$. Lamarckiana $\times 0$.gigas. In the polar views of the asters of the heterotype and homotype divisions of both these hybrids there are 7 distinct and perfect chromosomes to be seen, and amongst them many fragments. In the second generation of the cross between $O$. gigas and $O$. Lamarckiana the number of $2 x$ chromosomes has reverted to the original i 4 . Thus 'wenn die Chromosomen wirklich die Träger der erblichen Eigenschaften sind, genügen also 7 Chromosomen der 0 . gigas für die Vertretung aller erblichen gigas-Eigenschaften in diesen Hybriden' (p. I63).

It may be that the hybrid Primula makes use of some similar means, perhaps at the first segmentation division, whereby it eliminates its superfluous chromosomes.

Further interesting results have been recorded from crossing 0 . gigas with $O$. lata and $O$. Lamarckiana. De Vries (6) has found that when 
$O$. lata is crossed with $O$. gigas the F. I. generation shows 50 per cent. of a type intermediate between $O$. lata and $O$. gigas, and 50 per cent. intermediate between $O$. lamarckiana and $O$ gigas. Lutz (32) experimented on crossing $O$. lata with $O$. gigas, and from a study of forty hybrid plants was able to divide them into three classes, both in respect to their external characters and to their number of chromosomes: (I) lata type with I5 $(2 x)$ chromosomes; (2) gigas type with 30 ( $2 x$ ) chromosomes; and (3) intermediate type with 22 or $23(2 x)$ chromosomes.

\section{General Comparisons.}

It is proposed to limit this brief discussion to the manner of union of the lengths of spireme in the formation of the bivalent chromosome; to the cytological detail of the nuclei of hybrids, especially with regard to the number of their chromosomes; and to the fertile or sterile character of those hybrids.

Firstly, as regards the origin of the bivalent chromosome. A mass of controversial literature has accumulated round certain disputed points, especially concerning the significance of the parallel threads in the presynaptic stages and whether the union of the univalent spiremes in the formation of the bivalent chromosome may be described as telosynaptic (11) or parasynaptic (22), and consequently whether the fission in the spireme separates two whole univalent chromosomes or whether it is the premature fission in the substance of the univalent chromosome which will take effect in the homotype division.

This series of Primula does not throw any light on the meaning of the parallelisms in the heterotype prophases. During the long rest between the last premeiotic and first meiotic divisions all sequence of events is lost, so that it is impossible to trace any relationship between the parallel threads of the heterotype prophases and the chromosomes of the preceding mitosis. Neither can any relationship be established between the parallel threads of the heterotype prophases and the parallel lengths of post-synaptic spireme, for during synapsis all proceedings are hopelessly obscured. Therefore whether each thread represents the longitudinal half of a portion of a univalent chromosome, and the pairing is the preparation for the condensation to form the whole univalent chromosome, or whether, according to the view held by Grégoire (22), each thread represents a portion of a whole univalent chromosome, and the parallelism is the premature pairing of homologous chromosomes, is a problem which cannot be solved by the study of Primula alone. Perhaps both arrangements may be proceeding simultaneously in the presynaptic prophases. Moreover, the interpretation of the parallelisms does not materially affect the question as to the ultimate telosynaptic or parasynaptic origin of the bivalent chromosome, for it is the postsynaptic stages that elucidate this point. 
As the spireme comes out of synapsis it exhibits a certain amount of approximation between its lengths, but by the time that the open spireme stage is reached the spireme is thrown into loops, the sides of which are widely separated, the only places of union between them being the points of intersection. Gradually the sides of portions of the looped spireme approach one another, and thus indicate, in the still contimuous spireme, that association which will eventually result in the formation of the respective future bivalent chromosomes. The lateral association between the strands becomes increasingly more intimate. The spireme then segments. When the necessary blending of the two is accomplished, then the bivalent segment splits into its two univalent chromosomes. These retain their connexion during diakinesis and finally separate on the spindle of the first meiotic division.

Thus Primula clearly illustrates the views held by Farmer and Moore (11) regarding the telosynaptic arrangement of the univalent chromosomes in the spireme. It is evident that in the looping of the continuous spireme the future univalent chromosomes, which separate at the heterotype mitosis and are distributed between the two daughter nuclei, are arranged end to end, for each side of a loop becomes in process of time a univalent chromosome. As the loops fold over and the sides approximate there is secondarily a greater or a less degree of parasynapsis between them before their ultimate separation.

This telosynaptic origin of the bivalent chromosome is wonderfully clearly shown in Primula, both on account of the sharp definition of the spireme and also owing to the fact that in two of the Primulas examined there is no second contraction, so that the whole process of association, fusion, and splitting apart of the univalent spiremes can be traced in perfect sequence.

The univalent spireme of Primula is of even thickness and its outline so definite that the places where it forms a bivalent association are most obvious. This gives it a great advantage over some other forms in which the spireme is apparently very viscous, which makes it impossible to decide whether the strands are of the bivalent or of the univalent order, for they may be stretched into a fine thread or contracted into a broad ragged band.

Besides being regular in thickness, the spireme of Primula is almost invariably homogeneous. It has been shown that the spireme is univalent in nature, so that in the rare cases when fission in its substance has been seen it must be the premature appearance of the fission which will divide the univalent chromosomes at the homotype division.

Secondly, as regards the character of the nuclei of hybrids. As a rule hybrids are sterile, or partially so, but it is not a feature peculiar to them, as it has frequently been shown that pure races may be also largely sterile. Geerts (19) found that 50 per cent. of the pollen-grains of O. Lamarckiana 
were abortive. In a hybrid cotton plant obtained by crossing Gossypium Barbadense with $G$. herbaceum Cannon (2) observed that in the material collected in November and December most of the male cells were normal, whilst in the material collected in the spring amitosis occurred. Jenčič (26) has worked out the ratio of the sterile to the fertile pollen-grains in many hybrids. In the hybrid Primula austriaca, a cross between $P$. pannonica and $P$. acaulis, he found that between 50 and 60 per cent. of the pollengrains were sterile, and in the hybrid $P$. vemusta, a cross between $P$. carniolica and $P$. Auricula, that 42 per cent. were sterile.

It is generally accepted that the $2 x$ number of chromosomes in the hybrid is equivalent to the sum of the $x$ number of parental chromosomes, and in most cases this statement can be corroborated. One of the most convincing examples is to be found in the eggs of Ascaris. Herla (25) discovered that some Ascaris eggs possessed three chromosomes, of which two were larger than the third, and that the small chromosome was always isolated from the others. He concluded that it must have arisen from the univalens parent, but he was unable to verify the hybrid parentage. Zoja (41), later, definitely proved that the eggs with three chromosomes were the result of a cross between Ascaris megalocephala bivalens and A. megalocephala univalens. He confirmed Herla's supposition that the small chromosome was the paternal one, and hence concluded that 'la cromatina paterna e la materna restano indipendenti nel nucleo delle cellule embrionali'.

Again, the investigation of Rosenberg (33 and 34) on the hybrid Drosera obovata furnishes another convincing example of the fact that the hybrid possesses the sum of the $x$ numbers of the parental chromosomes. In the hybrid the Io $(x)$ chromosomes obtained from the parent $D$. rotundifolia pair with Io of the $(x)$ number of the chromosomes of the parent D. longifolia ; the remaining to chromosomes of $D$. longifolia remain unpaired. The ten bivalent chromosomes behave normally, but it seems to be a matter of chance to which pole the unpaired chromosomes repair, both in the heterotype and in the homotype divisions. Consequently the resulting tetrads possess a variable number of chromosomes. The pollen, as might be expected, is usually sterile. After several attempts Rosenberg has successfully crossed D. obovata with D. longifolia (34), and the offspring has about 37 chromosomes.

The recent work of Geerts (20) on the hybrid resulting from the cross between $O$. lata and $O$. gigas, and his interpretation of the union and behaviour of the parental chromosomes, are in direct accordance with the phenomena exhibited by the Drosera hybrid. On the other hand, Gates (16) has come to different conclusions as regards the behaviour of the chromosomes in the hybrid $O$. lata $\times 0$. gigas. He agrees with Geerts that, in the heterotype prophase of the hybrid, the chromosomes 
appear in their $2 x$ number, namely $2 \mathrm{I}$. No pairing of homologous chromosomes ensues, but ro move off to one pole and II to the other. "The IO-I I segregation of chromosomes in the formation of the germ cells of this hybrid shows that there is not here a pairing and separation of homologous chromosomes of maternal and paternal origin, but that the segregation tends to be into two numerically equal groups' (p. 195).

The hybrid fern Polypodium Schneideri (12) furnishes another example of an inequality in the number of the parental chromosomes, one parent having a far higher number than the other. The parent $P$. aureum has $35(x)$ chromosomes, the other parent, $P$. vulgare, var. elegantissimum, has about $90(x)$ chromosomes, and the number of chromosomes appearing at meiosis in the hybrid $P$. Schneideri varies from 95 to 125 . This figure can only be considered as an approximate estimate, as the chromosomes are so irregular and numerous, whilst at diakinesis some are apparently bivalent, and others univalent, that it is impossible to make an accurate count. The peculiar amitosis which is of such common occurrence in hybrids, and which may occasionally be found in pure strains, is frequently met with in $P$. Schneideri, dividing the pollen mothernuclei, first into two, and then into four. The spores of this hybrid fern are always abortive.

The above enumerated hybrids have parents possessing unequal numbers of chromosomes. There are other cases in which the parents possess the same number as in the case of $P$. kewensis (type). It has been shown that this hybrid, derived directly from $P$. floribunda crossed with $P$. verticillata, is sterile. On the other hand, Cannon (3) crossed two peas, both of which had I $4(2 x)$ and $7(x)$ chromosomes, and the hybrid which repeated the same number was fertile.

In certain ' race hybrids' of Lathyrus odoratus, Gregory (23) found that abortion took place at various stages in the course of the meiotic division. The chromosomes were more ragged than were those of the parents and showed a deficiency of chromatin. Sterility in this case is a recessive character and is generally confined to those plants which have light-coloured leaf axils, that being a recessive character.

Finally, there are those cases of hybrids in which the chromosomes of the parents are too numerous, and the spindles of the hybrids too irregular to afford accurate data as to the relative numbers of the chromosomes. Such is the case with the hybrid Syringa rothomagensis, a cross between $S$. vulgaris and $S$. persica. Juel (28) was unable to count the chromosomes, but he believes that there are more in the hybrid than in the parents. He finds very irregular spindles, and also the curious modification of amitosis. 'Bei so vielen Arten von Unregelmässigkeiten bei der Tetradentheilung kann es nicht Wunder nehmen, dass S. rothomagensis in Bezug auf den Blütenstaub fast steril ist' (p. 647). Tischler (39) has confirmed Juel's investigation 
of this hybrid, which he calls S. chinensis. Tischler (36) found in the hybrid Cytisus Adami, a cross between C. Laburnum and C.purpureus, most irregular divisions resulting in an unequal distribution of chromosomes to the poles. Again, in the hybrid Bryonia (37), a cross between B. alba and $B$. dioica, he has shown that the presynaptic and synaptic stages are normal, but that the chromosomes go on to the spindle irregularly, while some remain behind in the cytoplasm. The hybrid is always sterile. In the hybrid Ribes intermedium, a cross between $R$. sanguineum and $R$. nigrum (38), the meiotic phase is normal and Io to 5 per cent. of the pollen-grains are well developed.

The fact that a hybrid may be either sterile or fertile does not therefore appear to depend on the pairing of an equal number of parental homologous chromosomes, nor can the irregularity of the spindle figures be called a determinant of hybridity. It is true that irregular figures and the peculiar amitosis must entail an unequal partition of chromatin amongst the tetrads, and hence may render them functionless, but these abnormalities are not confined to hybrids, but may also occur in pure breeds. Juel (27) has emphasized this fact in the nuclei of Hemerocallis fulva.

Tischler and others believe that the arrangement of the chromosomes cannot be taken into account with regard to the cause of sterility, but that the sterile condition is more probably due to the poverty of the cytoplasm and to the alteration in the constitution of the idioplasm.

Most cytologists have arrived at the conclusion that, in the blending of the male and female germ cells, physiological and chemical changes are induced, which fundamentally disturb the metabolism of the cells of the resultant offspring. The abnormal nuclear phases, the anomalous behaviour of the chromosomes, and the feeble condition of the cytoplasm afford visible expressions of the influence of unrevealed agencies which effect these intrinsic changes.

In conclusion, it is of interest to emphasize the points of similarity between this series of Primulas and the varieties of Oenothera. Briefly the character of the heterotype prophases, the presence in some forms and the absence in others of the second contraction, the longitudinal fission in the chromosomes throughout the interkinesis of the two meiotic divisions, the cytoplasmic connexions between the pollen mother-cells, are all features which the Primulas possess in common with the Oenotheras.

Moreover, both in the Oenotheras and in the Primulas a form has arisen from different sources, which has suddenly doubled the number of the chromosomes characteristic of the type. From the Oenothera evidence it seems probable that this duplication has been brought about by longitudinal fission, creating what is believed to be a double set of homologous chromosomes, for the duplication of the chromosomes has not been accompanied by the acquirement of any new characters. On the other hand, in the case 
of $P$. kervensis, the duplication is accompanied by the acquirement of the character of fertility.

Further, both in the Oenotheras and in the Primulas, an example of a decrease in the chromosomes is found, whereby the duplicated number is reduced to the typical number. In the Oenotheras this reduction has been shown to be achieved by the actual disintegration of the supernumary chromosomes. It may be that in the hybrid produced by crossing $P$. flor $i$ bunda isabellina with $P$. kervensis (seedling form) a similar elimination of chromosomes has taken place in the first segmentation division after fertilization.

\section{SUMMARY.}

I. The parents, $P$. floribunda and $P$. verticillata of the sterile hybrid $P$. kewensis have both $\mathrm{I} 8(2 x)$ and $9(x)$ chromosomes.

This number is repeated in the sterile hybrid $P$. kewensis.

$P$. kewensis (seedling form), which originated from $P$. kewensis (sterile) by the fertilization of a pin flower with pollen of a thrum flower (both on the sterile stock), has doubled the typical number of chromosomes and possesses $3^{6}(2 x)$ and $18(x)$.

This number is repeated in the variety of the seedling form, $P$. kewensis farinosa, and reappears in the $P$. kewensis farinosa, which resulted from crossing $P$. verticillata with $P$. floribunda isabellina.

$P$. floribunda isabellina crossed with $P$. kewensis (seedling form) results in a hybrid which has reduced its chromosomes to the typical number of I $8(2 x)$ and $9(x)$.

2. The prophases of the premeiotic divisions show a stringing together of homogeneous beads of chromatin, which gradually condense to form the chromosomes. Longitudinal fission in the substance of the chromosomes is seldom seen until the chromosomes are arranged on the spindle.

3. The long rest between the last premeiotic and the first meiotic division makes it impossible to trace the homology of the parallel threads of the heterotype prophases.

4. In P. floribunda and in P. kewensis (seedling), there is no second contraction. Hence the sequence of events leading to the formation of the bivalent chromosomes can be traced without intermittence, namely, the looping of the contimuous univalent spireme; the approximation and association of the univalent sides of the loops ; and the final splitting apart of the approximated sides to form the univalent chromosomes of the bivalent combination.

5. This series illustrates clearly the telosynaptic arrangement of the univalent chromosomes in the continuous univalent spireme of the hollow spireme stage of the heterotype division, and the secondary parasynaptic union of homologous univalent segments to form the future bivalent heterotype chromosomes. 
6. In $P$. verticillata there is a typical second contraction.

In $P$. kervensis (type) the spireme segments tend to amalgamate in parts, but they never form a definite second contraction.

7. In $P$. kewensis (seedling form) two of the bivalent chromosomes join together in the heterotype prophase of the pollen mother-nuclei, forming a large quadrivalent chromosome. This union is maintained until its univalent portions separate on the spindle.

In the homotype division all the chromosomes behave normally. There is also no connexion between two of the chromosomes in the first meiotic division of the embryo-sac mother-cell.

8. P. kewensis (seedling form) has a most typical diakinesis. The chromosomes are extremely contracted and are widely separated from one another, but are connected together by fine tightly stretched threads. The ordinary bivalent chromosomes resemble dyads, the quadrivalent chromosome a tetrad.

9. Protrusions of chromatin from a nucleus into the adjacent cell are sometimes found in the 'open spireme' stage of $P$. kervensis (type).

In conclusion I wish to express my most grateful thanks to Professor J. Bretland Farmer, F.R.S., for the valuable help and advice that he has given me throughout the course of this work.

Royal College of Science, LONDON.

\section{BiBLIOGRAPHY.}

1. Agar, W. E. ("11): The Spermatogenesis of Lepidosiren paradoxa. Quart. Journ. Micr. Sci., lvii, Part I, August, pp. I-44.

2. Cannon, W. A. ('03): Studies in Plant Hybrids. The Spermatogenesis of Hybrid Cotton. Bull. of the Torrey Bot. Club, New York, xxx, No. 3, March, pp. I33-72.

3. ('03): Studies in Plant Hybrids. The Spermatogenesis of Hybrid Peas. Bull. of the Torrey Bot. Club, New York, xxx, No. 10, Oct., pp. 519-43.

4. Davis, B. M. ('09): Cytological Studies on Oenothera. I. Pollen Development of O. grandiflora. Ann. of Bot., xxiii, No. 92, Oct., pp. 55 I-7I.

5. ('10): Cytological Studies on Oenothera. II. The Reduction Divisions of Oenothera biennis. Ann. of Bot., xxiv, No. 96, Oct., pp. 63I-5I.

6. DE VRIEs, H. ('08): Bastarde von Oenothera gigas. Ber. deut. bot. Gesellsch., Berlin, xxvi, A, pp. $754-62$.

7. shire, Chicago.

8. Digby, L. ('09): Observations on Chromatin Bodies. Ann. of Bot., xxiii, No. 9I, July, pp. $49 \mathrm{I}-502$.

9. ('10): Nuclear Divisions of Galtonia candicans. Ann. of Bot., xxiv, No. 96, Oct., pp. $727-57$.

10. Farmer, J. B. ('95) : On Spore-Formation and Nuclear Division in the Hepaticae. Ann. of Bot., ix, No. 35, Sep., pp. 469-523. 
11. Farmer, J. B., and Moore, J. E. S. ('05): On the Meiotic Phase (Reduction Divisions) in Animals and Plants. Quart. Journ. Micr. Sc., xlviii, Part 4, Feb., pp. 489-557.

12. and DigBY, L. ('10): On the Cytological Features of Varietal and Hybrid Ferns. Ann. of Bot., xxiv, No. 93, Jan., pp. I9I-2I2.

13. Gardener's Chronicle ('00): xxvii, 3rd series, March 3, p. I30.

14. Gardener's Magazine ('00): April 2 I, p. 232.

15. Gates, R. R. ('08): A Study of Reduction in Oenothera rubrinervis. Bot. Gaz., Chicago, xlvi, No. I, July, pp. I-34.

16. ('09): The Behaviour of the Chromosomes in Oenothera lata $\times 0$. gigas. Bot. Gaz., Chicago, xlviii, No. 3, Sept., pp. I 79-99.

17. ('09): The Stature and Chromosomes of Oenothera gigas, de Vries. Archiv f. Zellforsch., Leipzig, iii, Heft 4, pp. 525-52.

18. ('10): The Chromosomes of Oenothera Mutants and Hybrids. Proc. International Zool. Congress, Cambridge (Mass.).

19. Geerts, J. M. ('09): Beiträge zur Kenntniss der Cytologie und der partiellen Sterilität von Oenothera Lamarckiana. Recueil des Trav. Bot. Néerlandais, Nimègue, v, livr. 2-4, pp. 93-209.

20. ('11): Cytologische Untersuchungen einiger Bastarden von Oenothera gigas. Ber. deut. bot. Gesellsch., Berlin, xxix, Heft 3, pp. I60-6.

21. GRÉGOIRE, V. ('06): La structure de l'élément chromosomique au repos et en division dans les cellules végétales. La Cellule, xxiii, $2^{\theta}$ fasc., pp. $3^{\mathrm{I}} \mathrm{I}-53$.

22. - ('10): Les Cinèses de maturation dans les Deux Règnes. ( ${ }^{\theta}$ Mémoire.) La Cellule, xxvi, $2^{\mathrm{e}}$ fasc., pp. 223-422.

23. Gregory, R. P. ('05): The Abortive Development of the Pollen in certain Sweet-Peas (Lathyrus odoratus). Proc. Cambridge Phil. Soc., xiii, Part 3, pp. I48-57.

24. ('09) : Note on the Histology of the Giant and Ordinary Forms of Primula sinensis. Proc. Cambridge Phil. Soc., xv, Part 3, pp. 239-46.

25. Herla, V. ('95): Étude des variations de la mitose chez l'Ascaride mégalocéphale. Arch. de Biol., Gand et Leipzig, xiii, pp. 423-520.

26. Jenčıč, A. ('00): Untersuchungen des Pollens hybrider Pflanzen. Öst. Bot. Zeit., 1, No. I, pp. I -5 and $4 \mathrm{I}-6$.

27. Juel, H. O. ('97): Die Kerntheilungen in den Pollenmutterzellen von Hemerocallis fulva und die bei denselben auftretenden Unregelmässigkeiten. Pringsh. Jahrb. f. wiss. Bot., Berlin, $\mathrm{xxx}, \mathrm{pp} .205^{-26}$.

28. - ('00) : Beiträge zur Kenntniss der Tetradentheilung. Pringsh. Jahrb. f. wiss. Bot., Leipzig, xxxv, pp. 626-59.

29. Kew Bulletin ('10): p. 325 .

30. Lawson, A. A. ('11): The Phase of the Nucleus known as Synapsis. Trans. of the Royal Soc. of Edinburgh, xlvii, Part 3, No. 20, pp. 59I-604.

31. Lutz, A. M. ('07) : A Preliminary Note on the Chromosomes of Oenothera Lamarckiana and one of its Mutants $O$. gigas. Science, N.S., New York, xxvi, Aug., pp. I5I-2.

32. - ('09): Notes on the First Generation Hybrid of Oenothera lata $\$ \times 0$. gigas 8 . Science, N.S., New York, xxix, Feb., pp. 263-7.

33. Rosenberg, O. ('03): Das Verhalten der Chromosomen in einer hybriden Pflanze. Ber. deut. bot. Gesellsch., Berlin, xxi, pp. I $10-19$.

34. ('09): Cytologische und morphologische Studien an Drosera longifolia $\times$ rotundifolia. Kungl. Svensk. Vet. Handl., Upsala and Stockholm, xliii, No. I I, pp. 3-64.

35. Strasburger, E. ('10): Über geschlechtbestimmende Ursachen. Pringsh. Jahrb. f. wiss. Bot., Leipzig, xlviii, 4. Heft, pp. 427-520.

36. Tischler, G. ('03): Über eine merkwürdige Wachstumserscheinung in den Samenanlagen von Cytisus Adami, Poir. Ber. deut. bot. Gesellsch., Berlin, xxi, pp. 82-9.

37. ('06): Über die Entwicklung der Sexualorgane bei einem sterilen Bryonia-Bastard. Ber. deut. bot. Gesellsch., Berlin, xxiv, pp. 83-96.

38. ('06): Über die Entwicklung des Pollens und der Tapetenzellen bei RibesHybriden. Pringsh. Jahrb. f. wiss. Bot., Leipzig, xlii, 4. Heft, pp. 545-78.

39. ('08): Zellstudien an sterilen Bastardpflanzen. Arch. f. Zellforschung, Leipzig, i, I. Heft, pp. $33^{-1} 5^{\text {I. }}$ 
40. Tischler, G. ('10): Untersuchungen iiber die Entwicklung des Bananen-Pollens, I. Arch. f. Zellforschung, Leipzig, v, 4. Heft, pp. 622-70.

41. Zoja, R. ('96) : Sulla indipendenza della cromatina paterna e materna nel nucleo delle cellule embrionali. Anat. Anzeig., Jena, xi, No. Io, Nov., pp. 289-93.

\section{EXPLANATION OF PLATES XLI-XLIV.}

Illustrating Miss Digby's paper on the Cytology of hybrid Primulas.

All the figures were drawn with the camera lucida under a $2 \mathrm{~mm}$. apochr. Hom. imm. Zeiss, N.A. I•40, with comp. oc. $18 . \times 2,25$.

Figs. I-6. P. kewensis (seedling form). Premeiotic divisions.

Figs. 7-42. P. floribunda. Meiosis.

Figs. 43-53. $P$. verticillata. First meiotic division.

Figs. 54-7I. P. kewensis (type). Meiosis.

Figs. 72-106. P. kewensis (seedling form). Meiosis.

Figs. 107 and 108. P. kewensis farinosa.

\section{PLATE XLI.}

Fig. I. P. kewensis (seedling form). Premeiotic divisions. Telophase.

Fig. 2. Late telophase or resting stage.

Fig. 3. Early prophase showing the stringing together of beads of chromatin.

Fig. 4. Concentration of beads to form the chromosomes.

Fig. 5. The chromosomes gradually become homogeneous.

Fig. 6. Fully developed chromosomes.

Fig. 7. P. floribunda. Pollen mother-cell. Resting stage between the premeiotic and first meiotic division. The nucleolus buds freely.

Fig. 8. Complete resting stage. The nucleus appears empty except for a few large rounded chromatic masses, and some smaller chromatin granules.

Fig. 9. Early prophase. The nuclear contents have increased owing to the continuous nucleolar budding.

Fig. Io. The nucleus is considerably larger, and the chromatin granules are more definitely arranged on linin strands.

Fig. II. The linin strands tend to run parallel to one another.

Fig. I 2. The earliest stage in the massing of the granules preparatory to synapsis.

Fig. I3. Further concentration of the granules into groups.

Fig. I 4. Synapsis.

Fig. I5. Loosening of the synaptic knot.

Fig. 16. Lengths of spireme come out of synapsis showing bifurcated ends.

Fig. I7. Spireme emerging from synapsis in the form of loops.

Fig. I8. Superficial section of loosening synaptic knot, showing ladder-like association of lengths of spireme.

Fig. I9. Opening out of the loops of spireme.

Fig. 20. Hollow spireme.

Fig. 21. The loops of the hollow spireme withdraw from the periphery of the nucleus, the sides of each loop tend to approach one another and to join in places.

Fig. 22. Closer association of the sides of each loop. Note the chromatic swelling at the points of union.

Fig. 23. The associated sides of each loop form more definite figures.

Fig. 24. Each bivalent segment dissociates itself from its neighbours.

Fig. 25. Maximum degree of concentration of the univalent strands in the bivalent combination.

Fig. 26. Nucleus showing some of the univalent strands approximated to form thick bivalent segments, whilst others still form the sides of open loops, united at intervals.

Fig. 27. The limits of the nine bivalent segments (chromosomes) can now be identified.

Fig. 28. The splitting apart of the two univalent chromosomes.

Fig. 29. L.ater stage in the separation of the univalent chromosomes. 


\section{and of other related Primula Hybrids.}

Fig. 30. Shows the chromatic swelling where the two univalent chromosomes are still in contact.

Fig. 3I. The univalent sides have diverged and concentrated to form the typical heterotype chromosomes.

Fig. 32. Origin of the quadripolar spindle.

Fig. 33. The chromosomes arrange themselves on the equatorial plate. Note the laggard chromosome.

Fig. 34. Polar view of the equatorial plate of the first meiotic division, showing the nine chromosomes.

\section{PLATE XLII.}

Fig. 35. Chromosomes separating and passing to the poles.

Fig. 36. Telophase of the first meiotic division. Protoplasmic connexions streaming through the cell-walls join spindles of adjacent cells to one another.

Fig. 37. Late telophase. The chromosomes split longitudinally and their sides are beaded.

Fig. 38. Resting stage. The skeleton of each chromosome is outlined in beads.

Fig. 39. Reconstitution of chromosomes. division.

Fig. 40. Longitudinally split chromosomes going on to the spindle of the second meioiic

Fig. 4I. Homotype spindle showing the nine chromosomes.

Fig. 42. Telophase of second meiotic division.

Fig. 43. P. verticillata. Pollen mother-cell. Spireme coming out of synapsis; tracts coalesce, forming a band-like chromatic mass, the beginning of the second contraction.

Fig. 44. The mass has increased in size.

Fig. 45. Second contraction from which radiate irregular loops of spireme.

Fig. 46. Sorting out of the second contraction. The protruding portions show all stages in the association of univalent strands.

Fig. 47. The chromosomes may come out of second contraction in the form of chains of rings.

Fig. 48. The chromosomes tend to segregate into two groups.

Fig. 49. Shows longitudinal fission in the substance of the newly separated, univalent chromosomes.

Fig. 50. The splitting apart of the univalent chromosomes.

Fig. 5I. Condensation of the univalent chromosomes to form the typical heterotype chromosomes.

Fig. 52. Polar view of an equatorial plate of the first meiotic division.

Fig. 53. Interkinesis between the first and second meiotic divisions.

Fig. 54. P. kewensis (type). Pollen mother-cell. Hollow spireme, showing the association of the sides of the loops.

Fig. 55. Protrusion of chromatin from a nucleus into the adjacent cell.

Fig. 56. Arrangement of beaded strands of spireme into squares and parallel lines.

Fig. 57. Concentration of these associations to form the bivalent segments.

Fig. 58. Further concentration of univalent strands into ladder-like associations. The strands coalesce in places.

Fig. 59. Splitting apart of the univalent segments of each bivalent combination.

Fig. 6o. Further stage in the splitting apart of the univalent chromosomes, and their subsequent thickening.

Fig. 61. The thickened ring-shaped chromosomes tend to collect together into one or two groups. loops.

Fig. 62. As they redistribute themselves throughout the nucleus they often appear as chains of

Fig. 63. The opening out of the rings to form the bivalent chromosomes.

Fig. 64. Typical heterotype chromosomes.

Fig. 65. Polar view of an equatorial plate of the first meiotic division, showing the nine chromosomes.

Fig. 66. Separation of the univalent chromosomes on the spindle.

Fig. 67. Tetrad.

\section{PLATE XLIII.}

Fig. 68. Pollen-grain apparently normal.

Fig. 69. Pollen-grain depauperate.

Fig. 70. Nucellus. Prophase showing eighteen chromosomes. 
Fig. 7I. Embryo-sac mother-cell. Prophase of first meiotic division, showing nine chromosomes.

Fig. 72. P. kewensis (seedling form). Synapsis. Note budding of the nucleolus.

Fig. 73. Hollow spireme; large round masses of chromatin lie within the meshes.

Fig. 74. The chromatin masses become absorbed, and an association between univalent portions of spireme begins to be seen.

Fig. 75. The thin strands of spireme, carrying beads of chromatin, lie parallel to one another and fuse in places.

Fig. 76. The paired univalent segments form definite bivalent combinations, the future bivalent chromosomes.

Fig. 77. The univalent segments become beaded.

Fig. 78. The limits of the beaded chromosomes can now be distinctly seen.

Fig. 79. Two of the bivalent chromosomes may be joined together.

Fig. 8o. The chromosomes tend to lose their beaded character. Note two bivalent chromosomes are joined together.

Fig. 8I. The univalent chromosomes thicken, and become more homogeneously chromatic.

Fig. 82. Slightly later stage in which the chromosomes are more definite, some being still beaded whilst others are concentrated.

Fig. 83 . The univalent chromosomes begin to contract. The quadrivalent chromosome is most apparent.

Fig. 84. The contracted chromosomes once more become beaded.

Fig. 85. Contraction proceeds, resulting in an extremely beaded condition of the chromosomes.

Fig. 86. Same stage as Fig. 85. The large chromosome is to be seen.

Fig. 87. The chromatin of the beads diffuses throughout the linin, and the chromosomes increase in size.

Fig. 88. The chromosomes become more homogeneous.

Fig. 89. Typical diakinesis. The bivalent chromosomes resemble dyads, the quadrivalent chromosome a tetrad.

Fig. 90. Same stage as Fig. 89.

Fig. 91. Some shapes adopted by the quadrivalent chromosome.

Fig. 92. Droplets of nucleolar material attached to the chromosomes.

Fig. 93. Chromosomes going on the spindle. Note the quadrivalent chromosome.

Fig. 94. Equatorial plate of the first meiotic division. The quadrivalent chromosome is separating into its univalent segments.

Fig. 95. The bivalent chromosomes are beginning to separate into their univalent parts. The quadrivalent chromosome is still a ring.

Fig. 96. Polar view of an equatorial plate of the first meiotic division, showing eighteen chromosomes.

Fig. 97. Passing of the univalent chromosome to the poles. Note the separation of the chromosomes of the quadrivalent union.

\section{PLATE XLIV.}

Fig. 98. The chromosomes approach the poles.

Fig. 99. Polar view of an aster of the first meiotic division, showing the eighteen chromosomes.

Fig. 100. Early telophase.

Fig. IOI. The chromosomes begin to separate and a nuclear limiting membrane appears.

Fig. 102. Later telophase. The chromosomes are all distinct and separate.

Fig. 103. Interkinesis between the first and second meiotic divisions, showing the split chromosomes.

Fig. 104. Embryo-sac mother-cell. Prophase of the first meiotic division. The chromosomes are all separate from one another. Note seventeen chromosomes and one in the next section.

Fig. 105. Embryo-sac mother-cell. Equatorial plate (in two consecutive sections). All the chromosomes are of the same size, and there is no quadrivalent combination.

Fig. 106. Embryo-sac mother-cell. Polar view of equatorial plate, showing the eighteen chromosomes.

Fig. 107. P. kewensis farinosa (varietal origin). First meiotic division. Polar view of aster, showing eighteen haploid chromosomes.

Fig. 108. P. kezvensis farinosa (hybrid origin). Premeiotic prophase, showing thirty-six diploid chromosomes. 
Annals of Botany
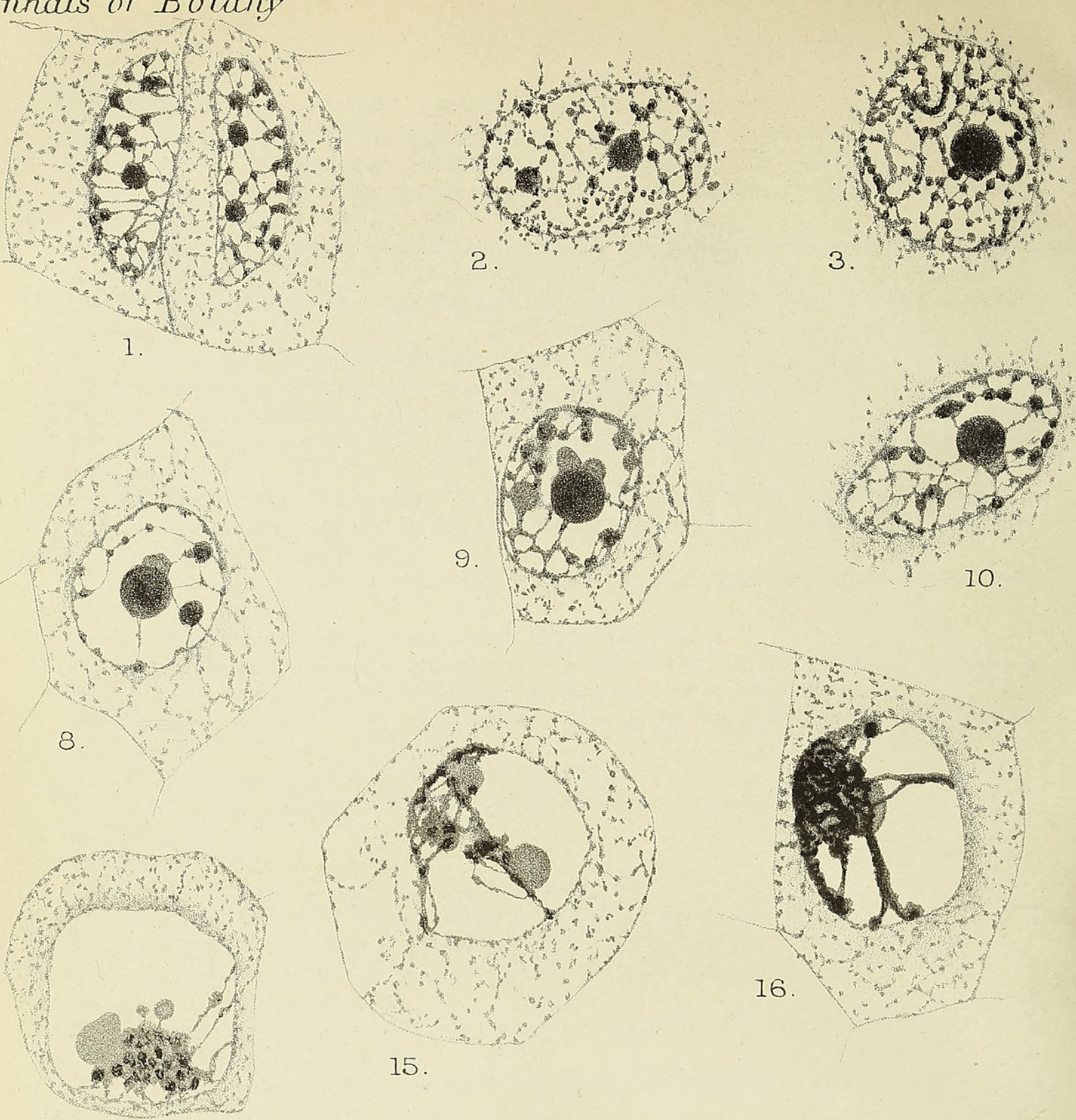

14
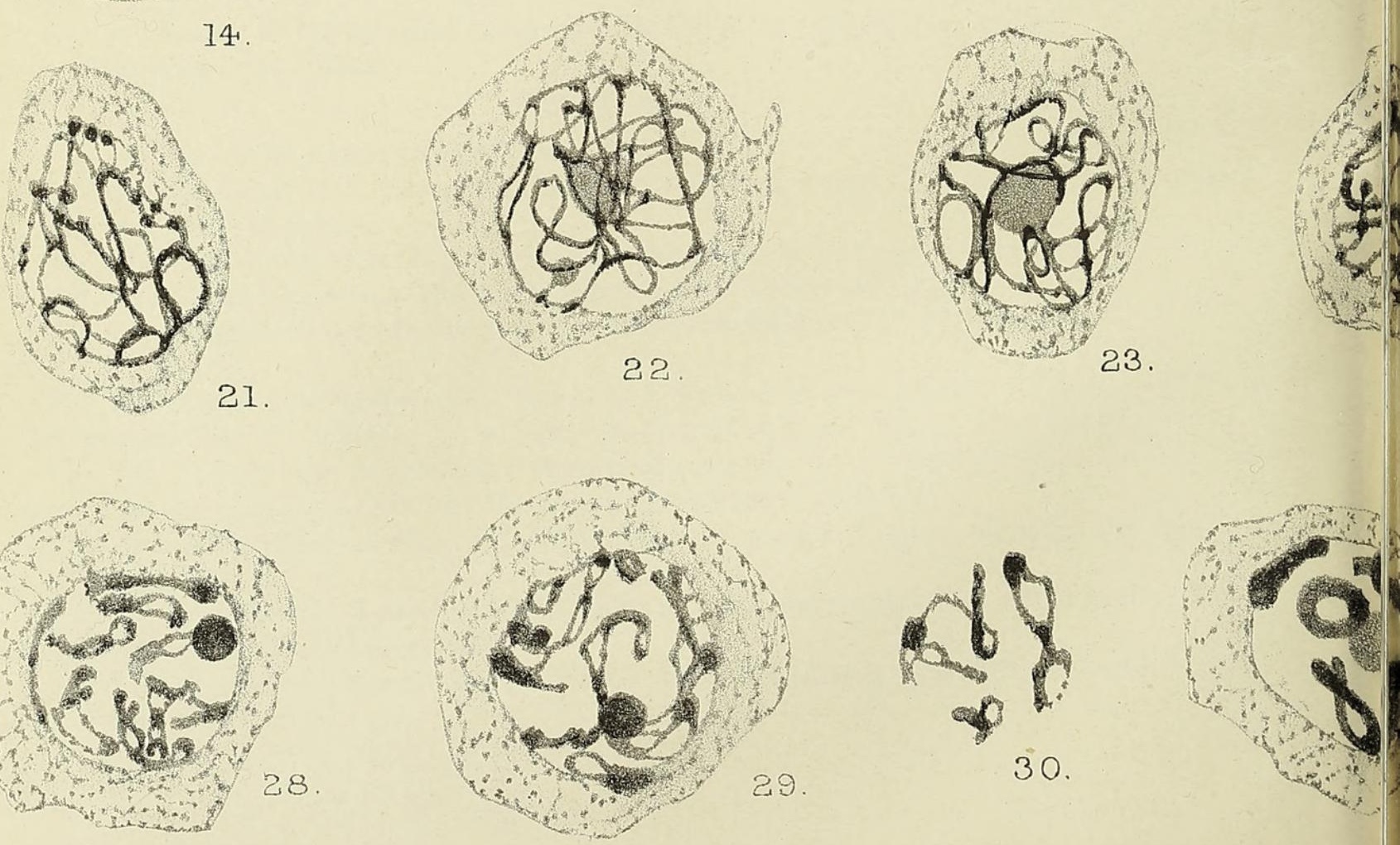

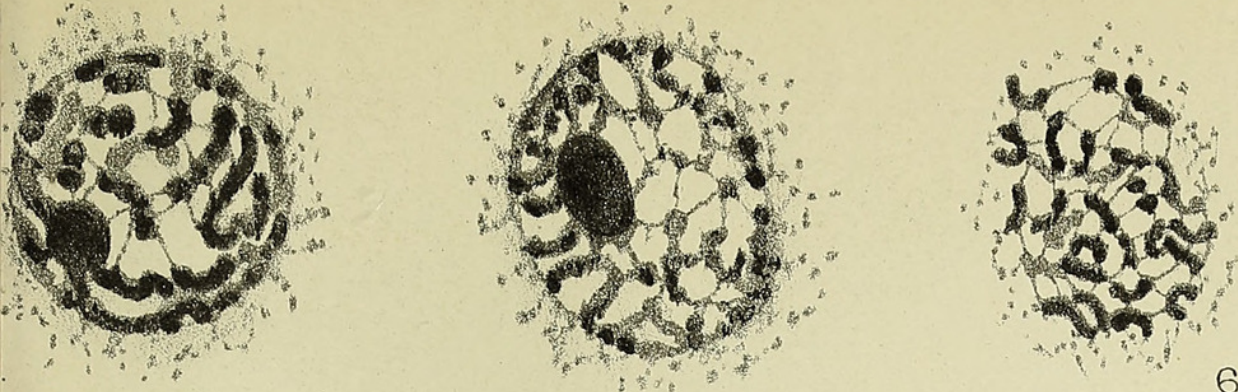

5.

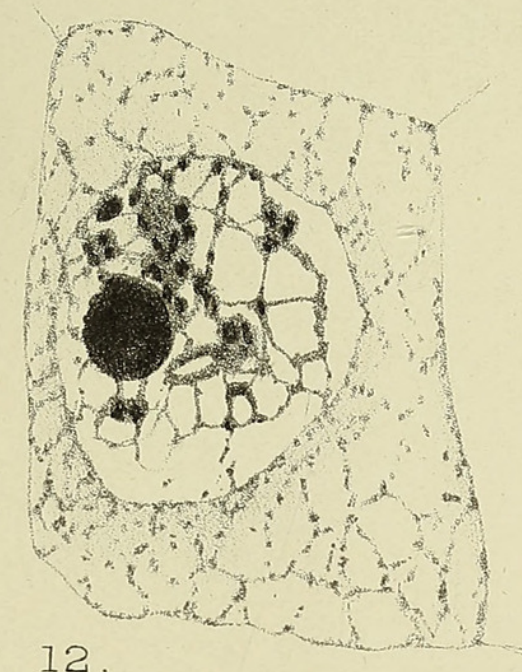

12
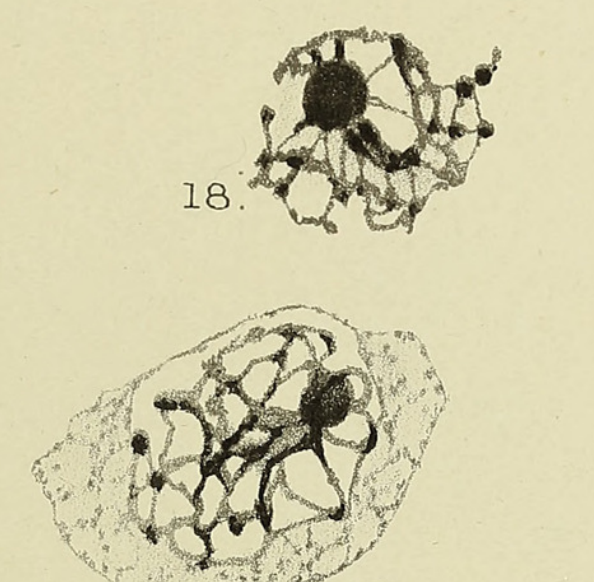

19.
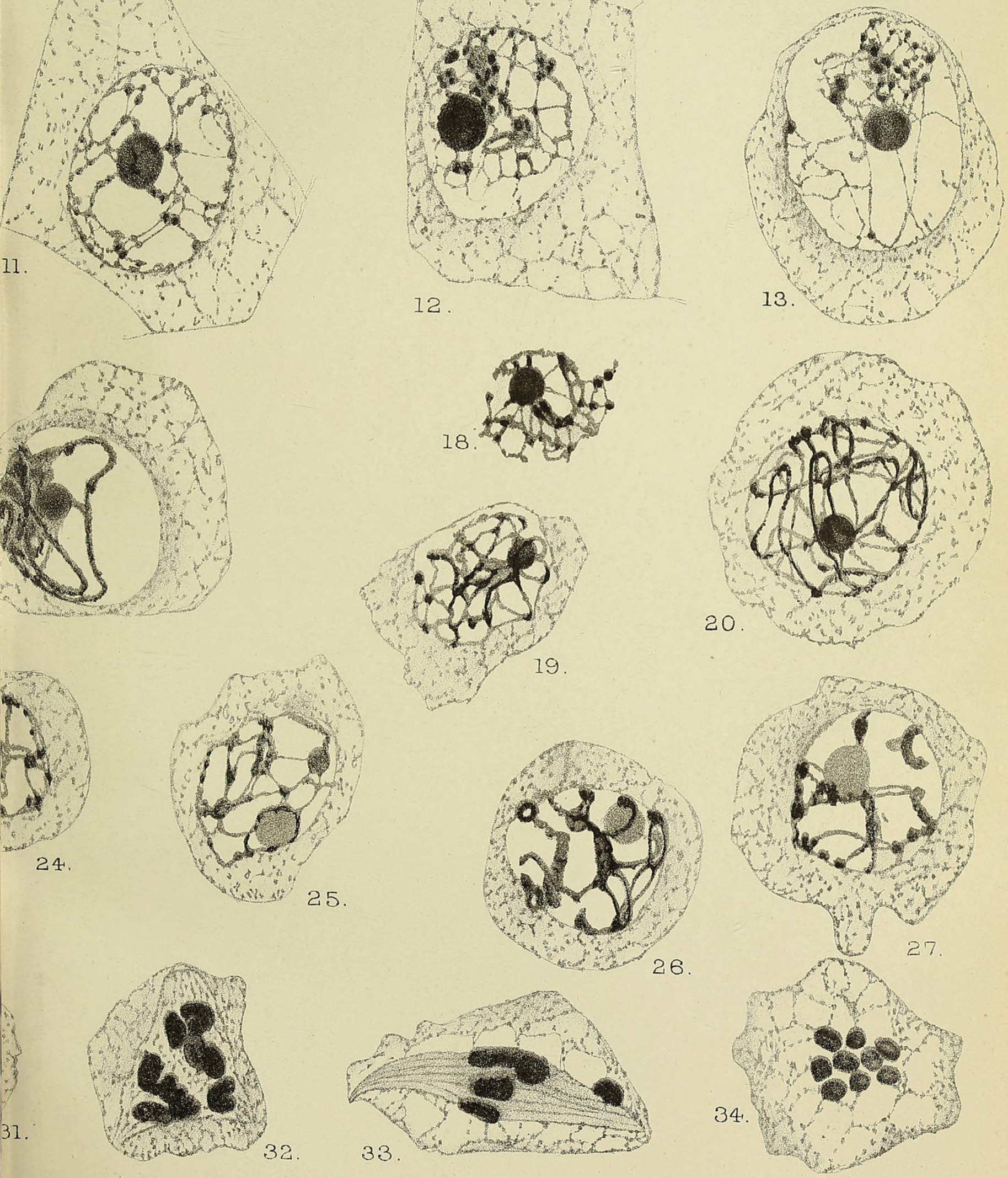

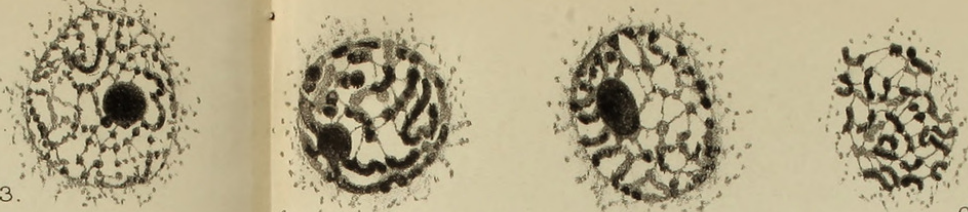

Vol. XXVI. Pl.XII
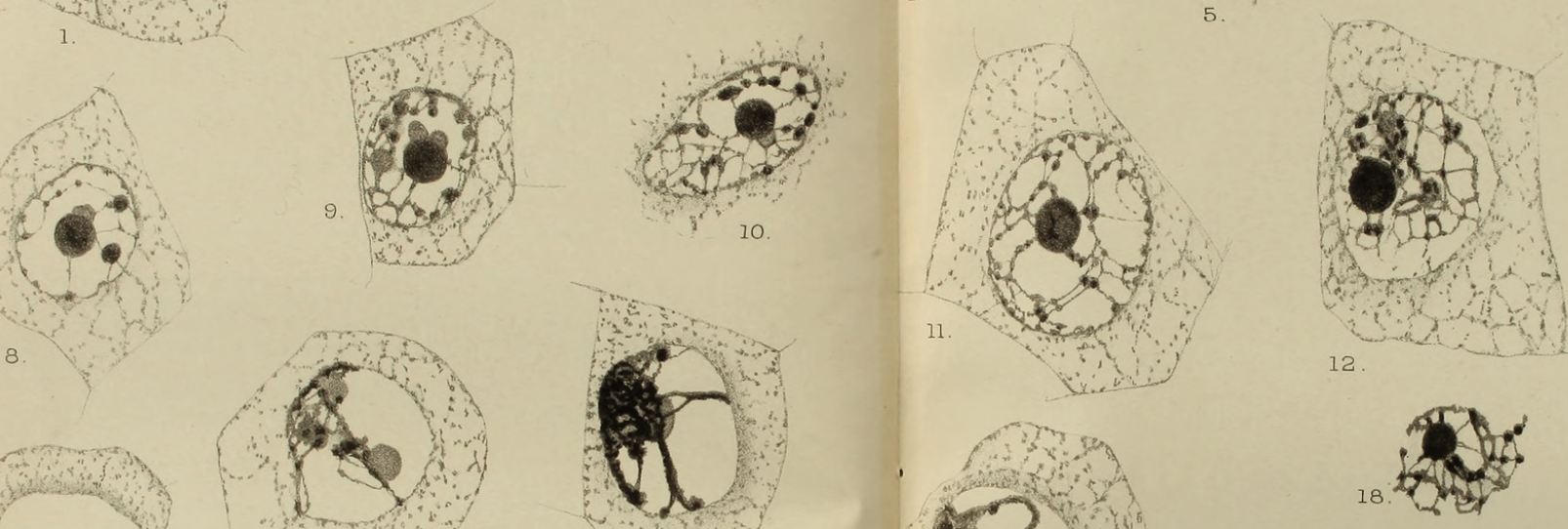

政
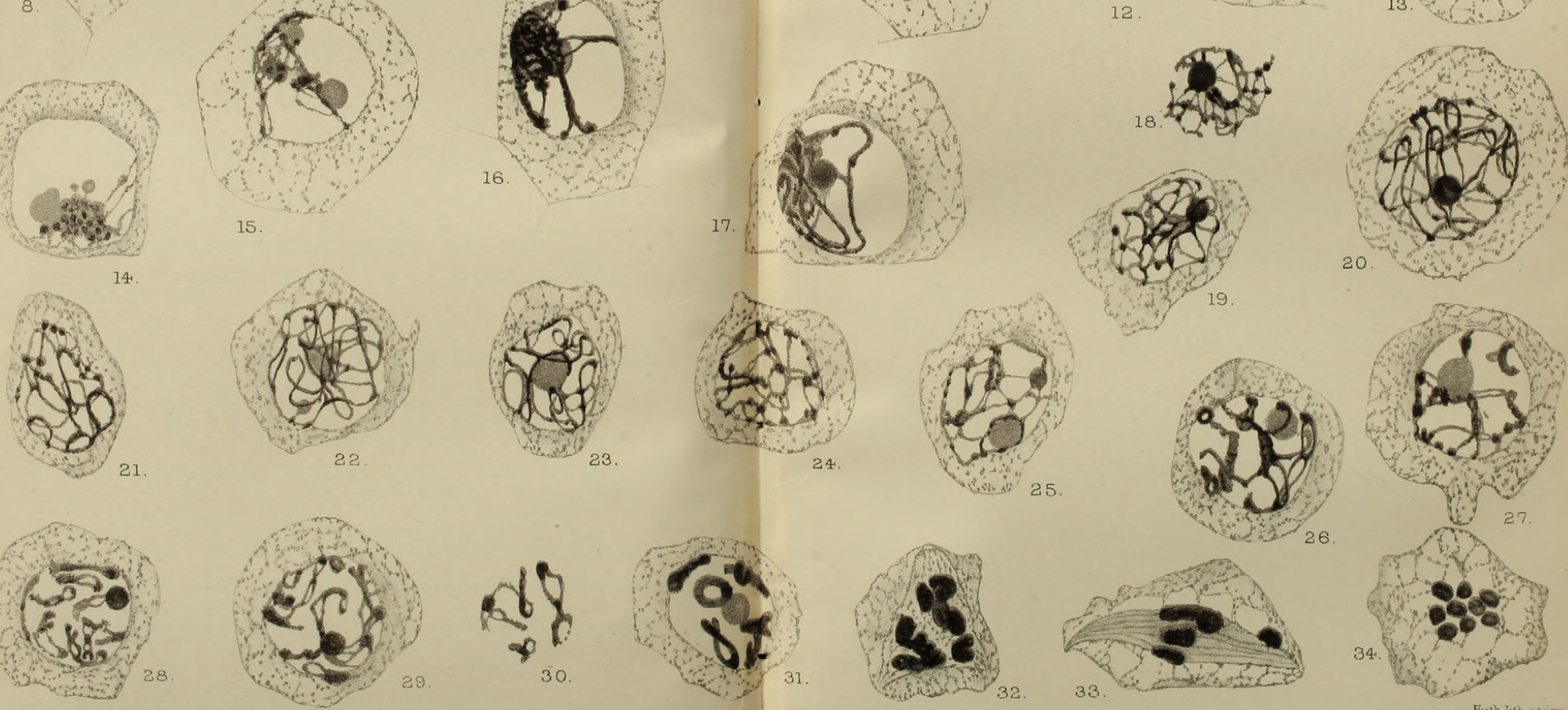
Annals of Botany.

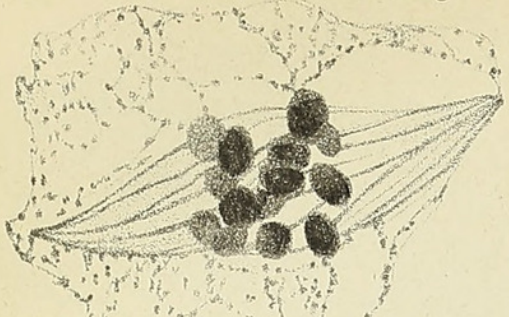

35.
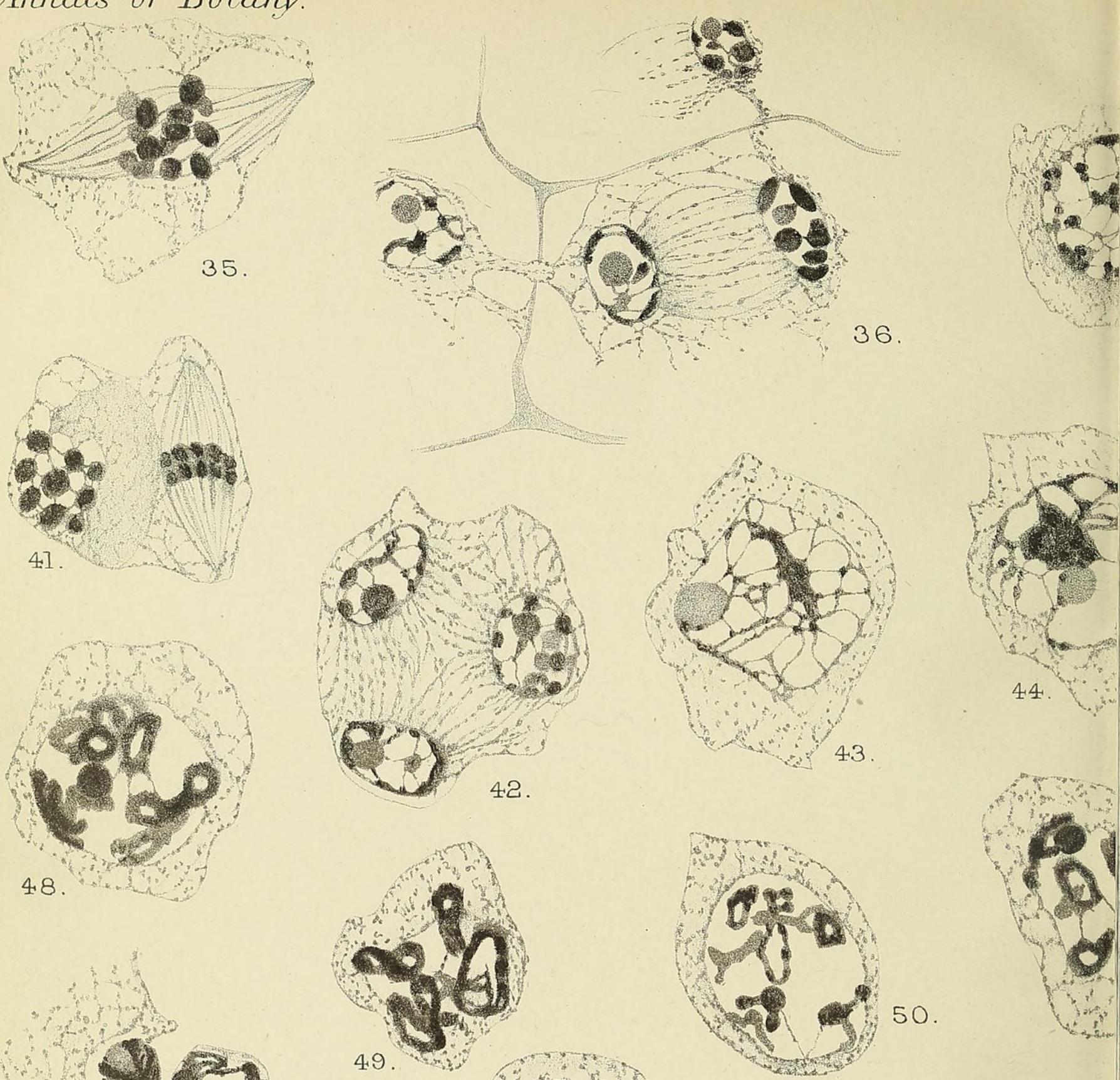

48
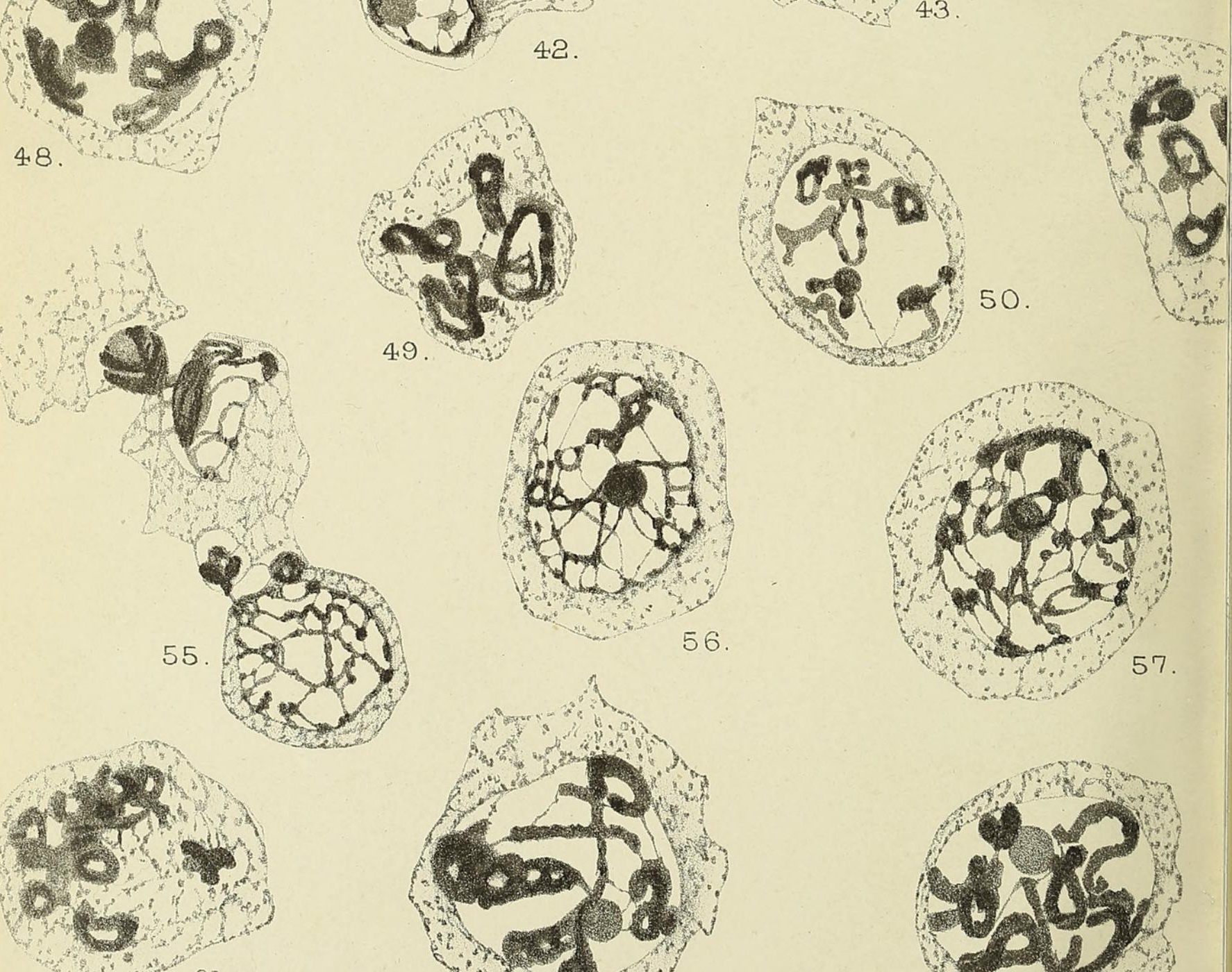

56.

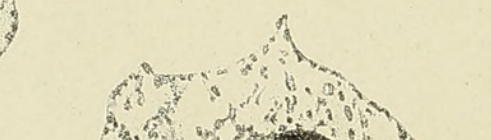



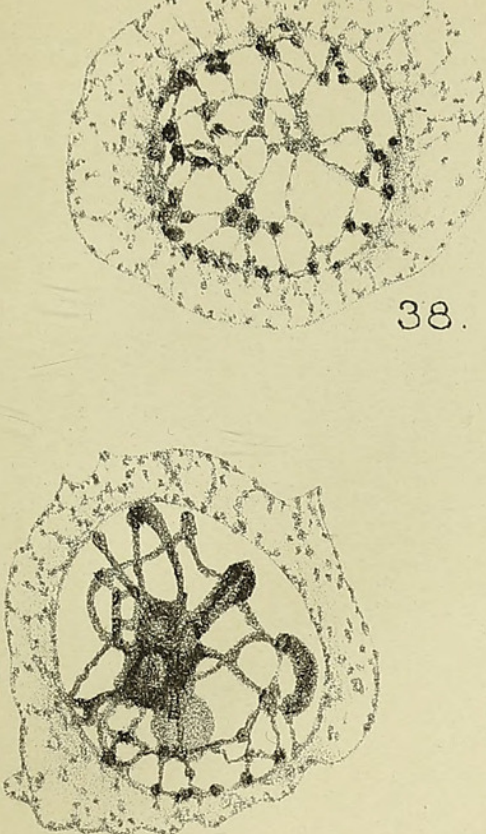

45.
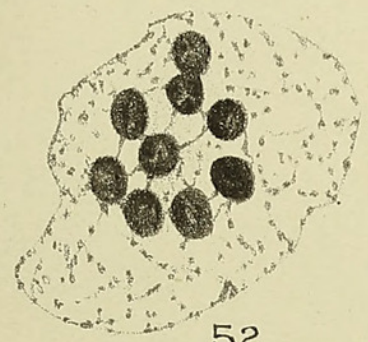

52
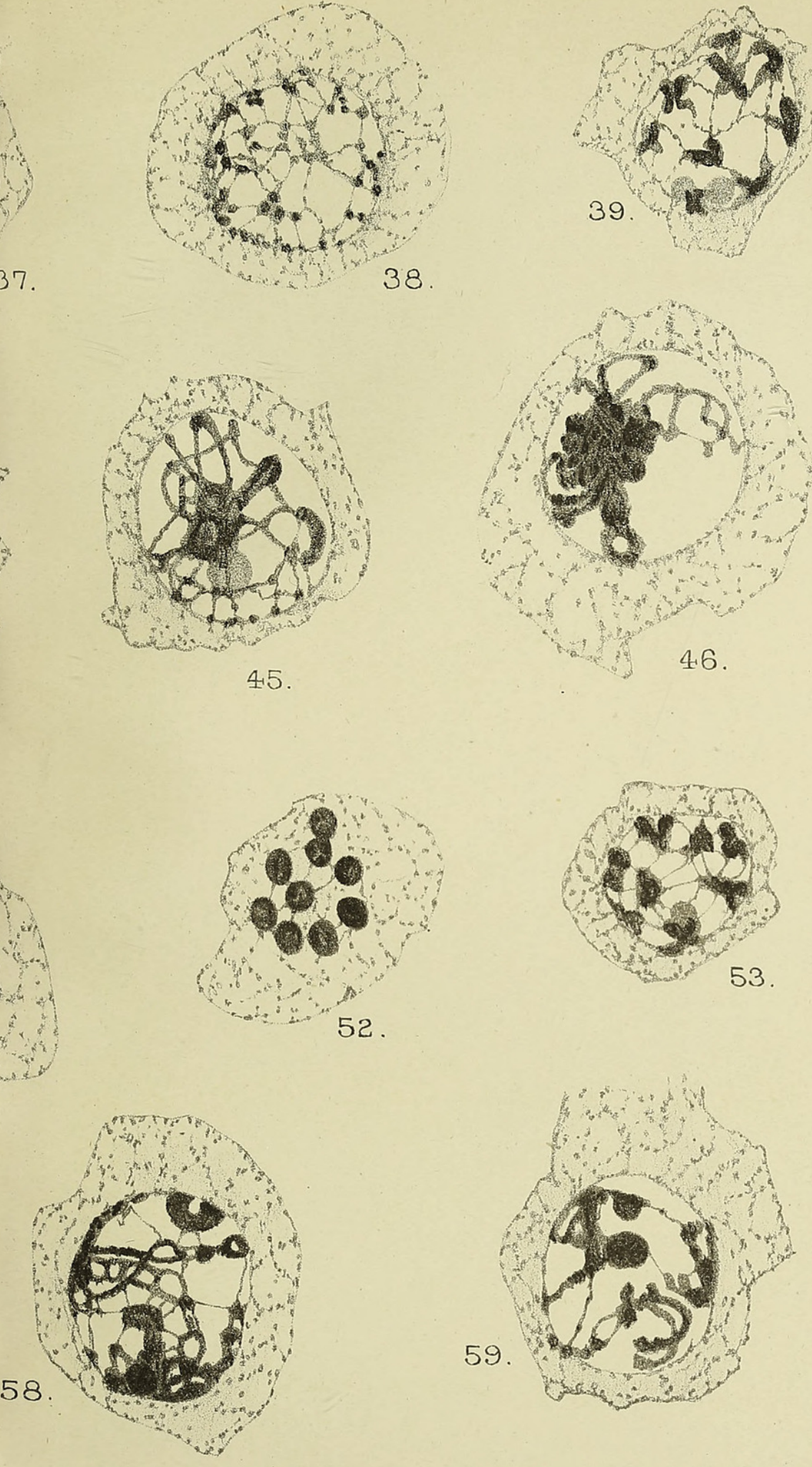

Vol. XXVI. PL. XLII
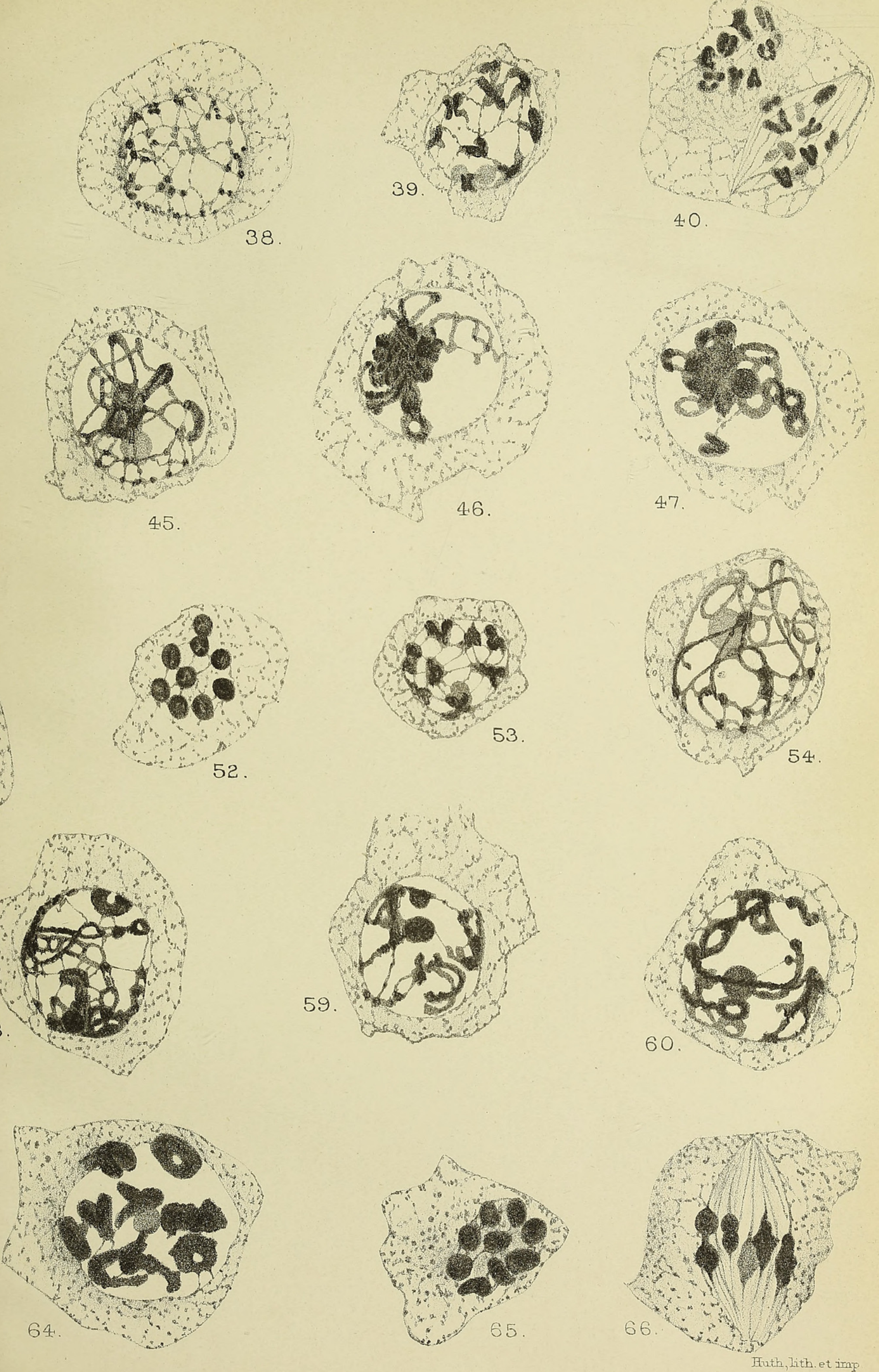


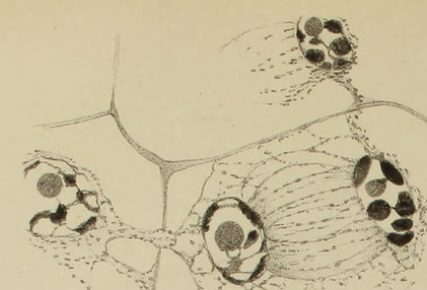

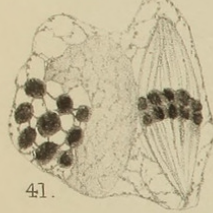
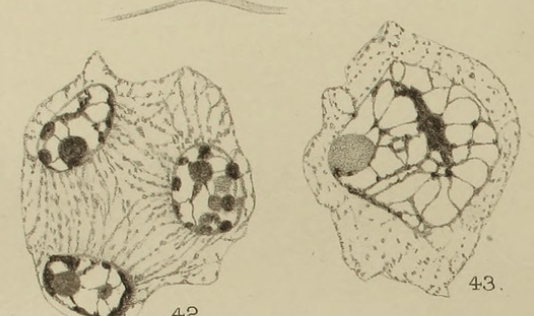

8

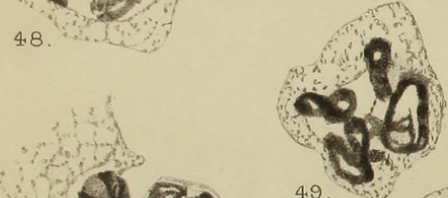

9 (e)

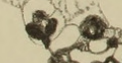

5. 20
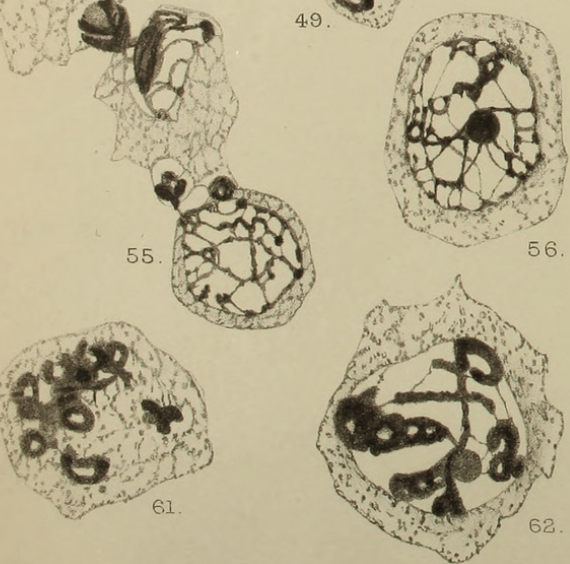
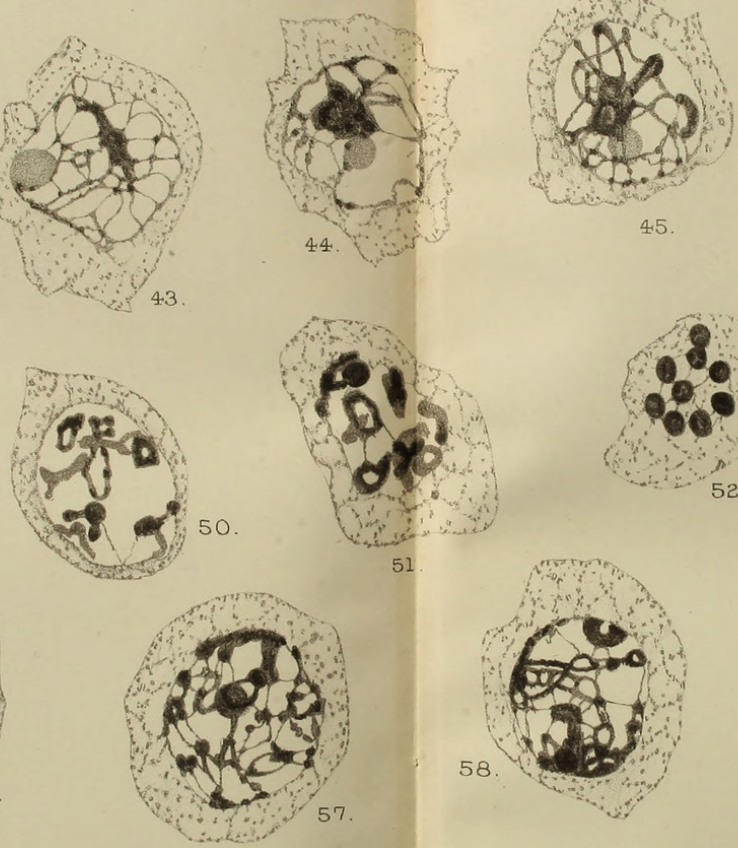

51.
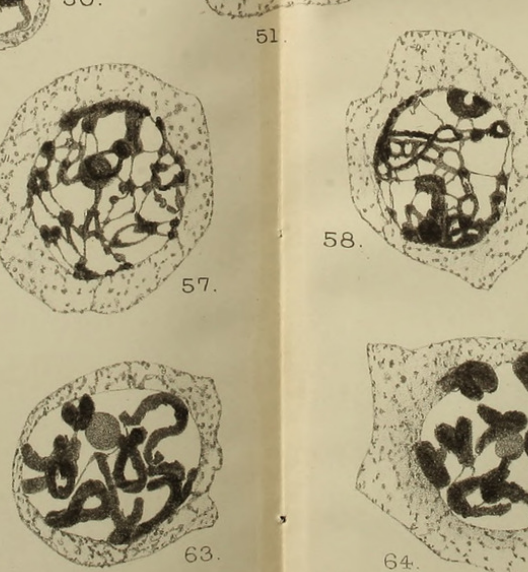
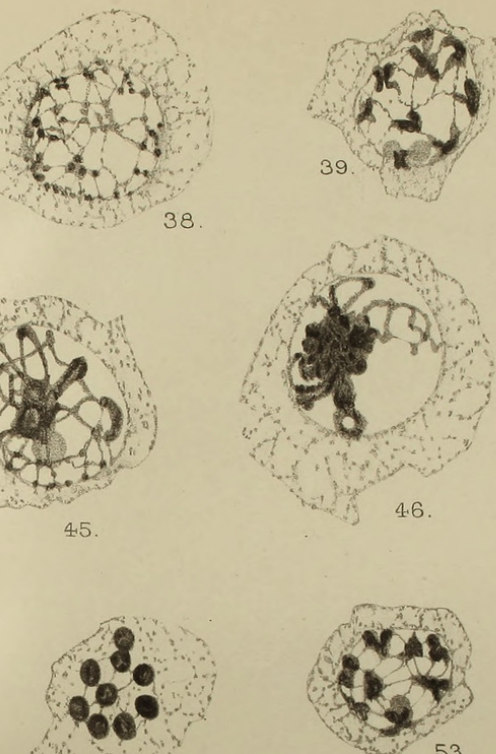

Vol. XXVI. PL. XLII.
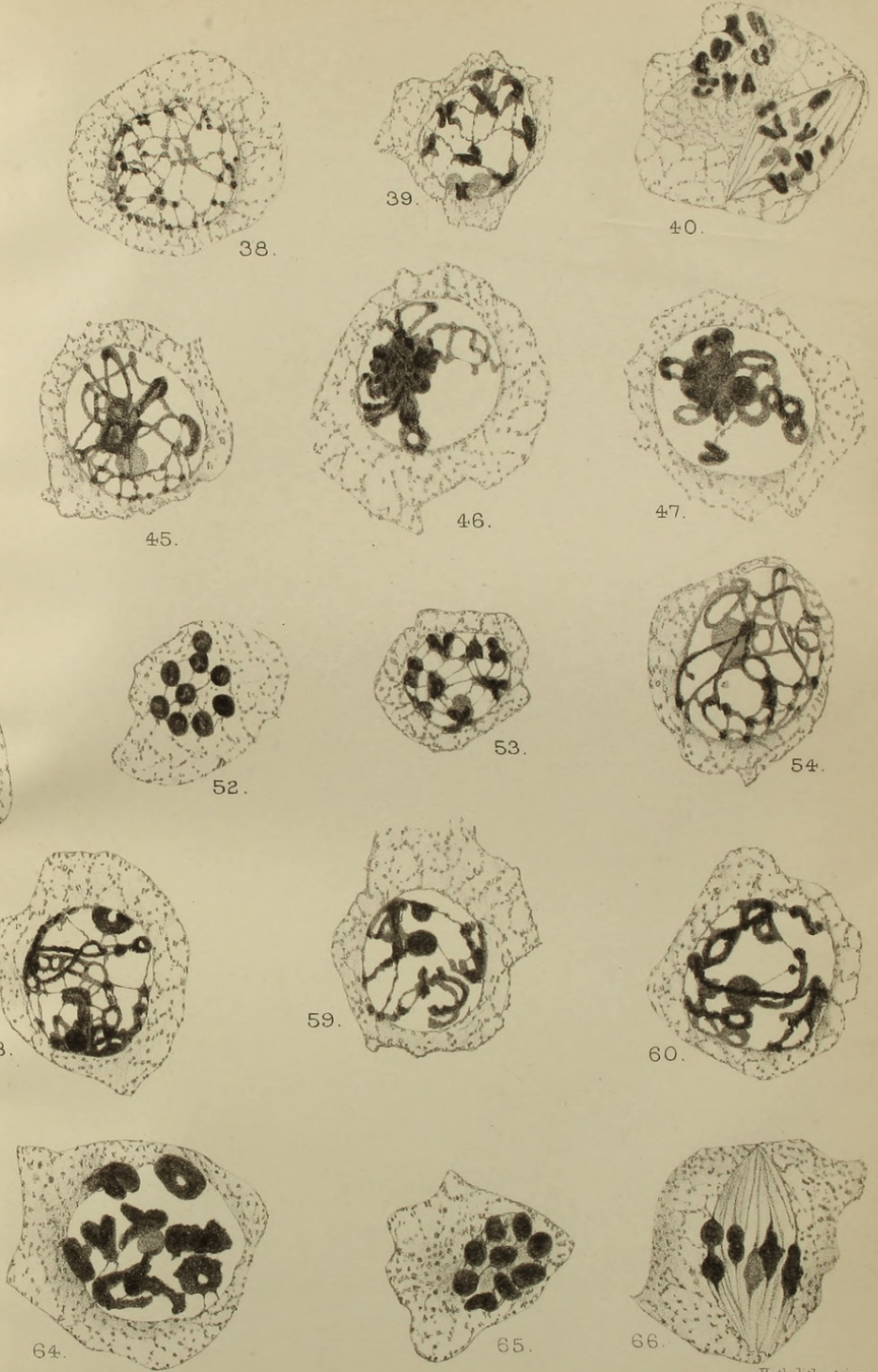
Annals of Botany.

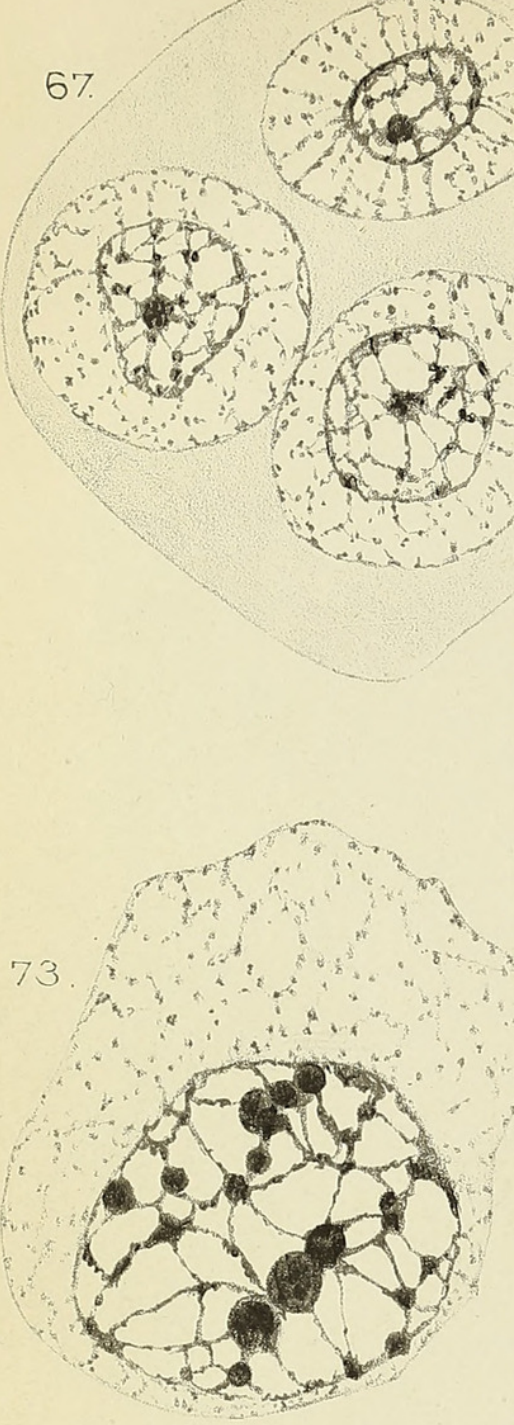

68

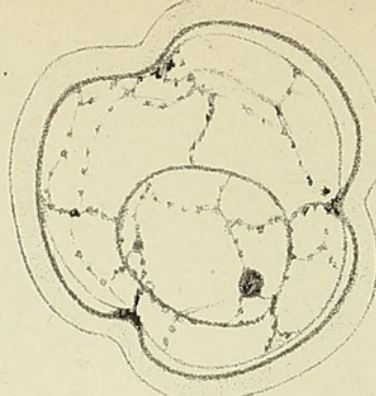

69.

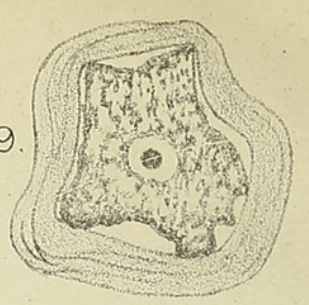

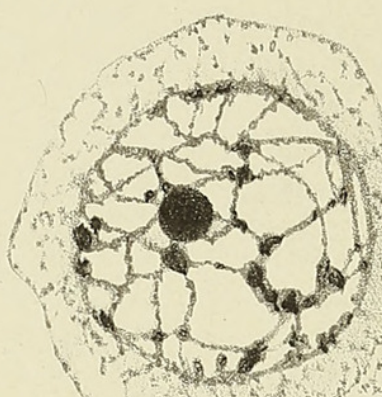

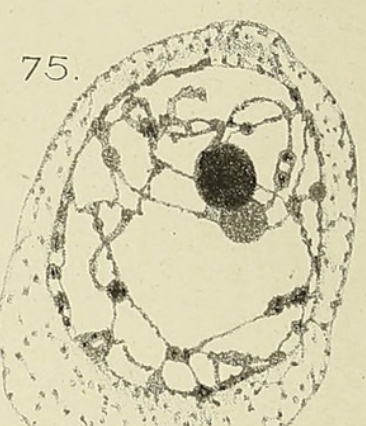

\section{4}

76

:
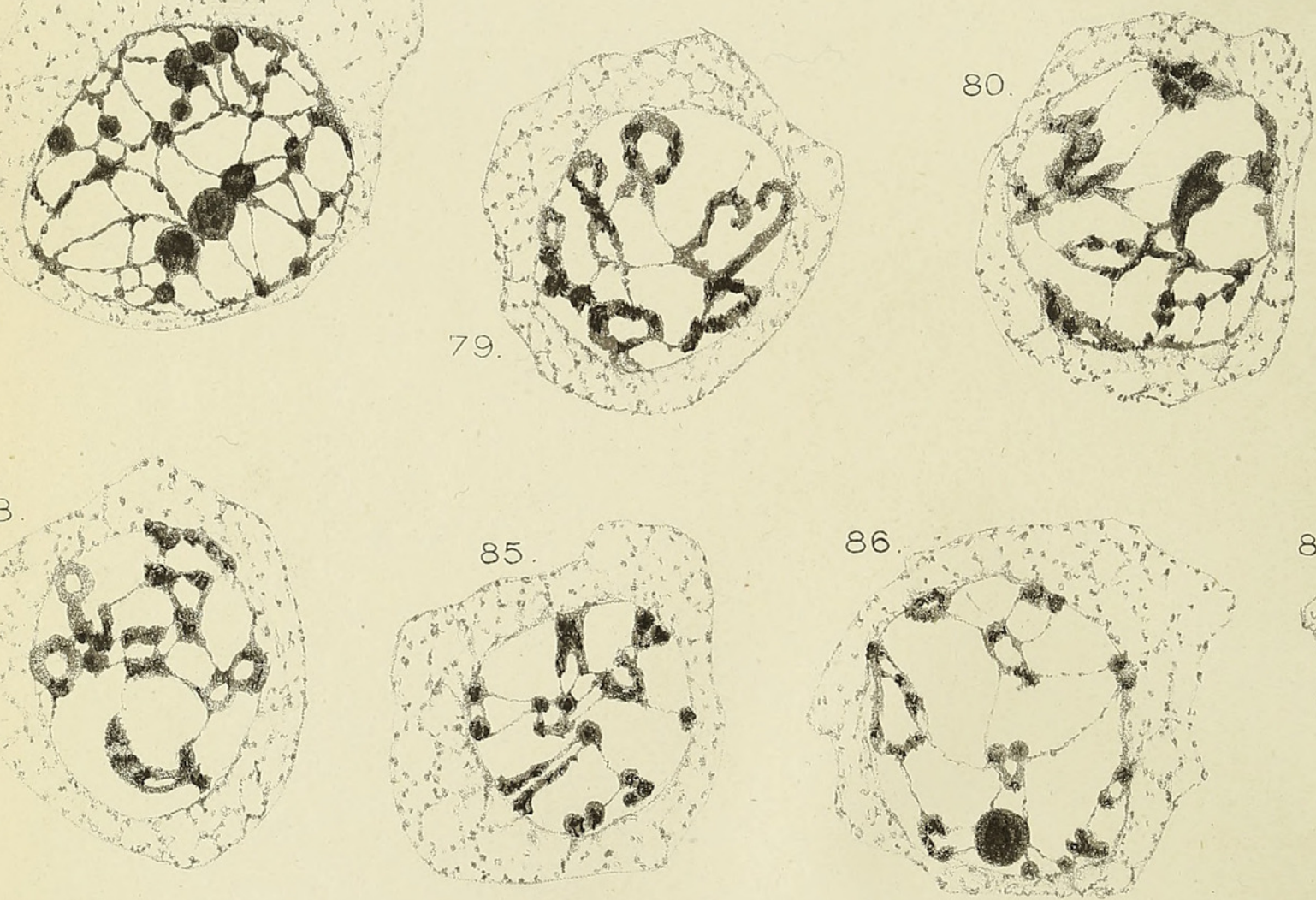

87.

81. 

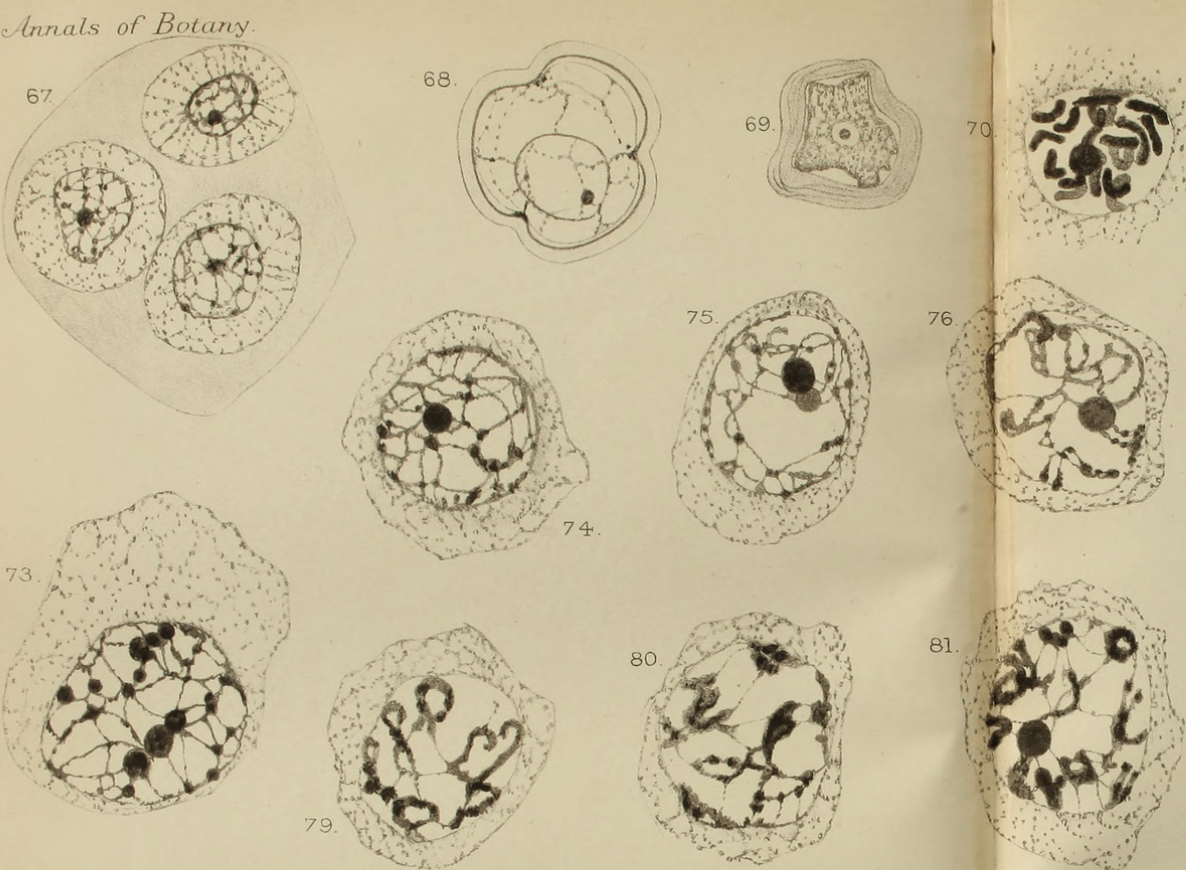

8

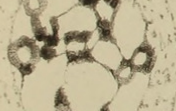

\% 8 :
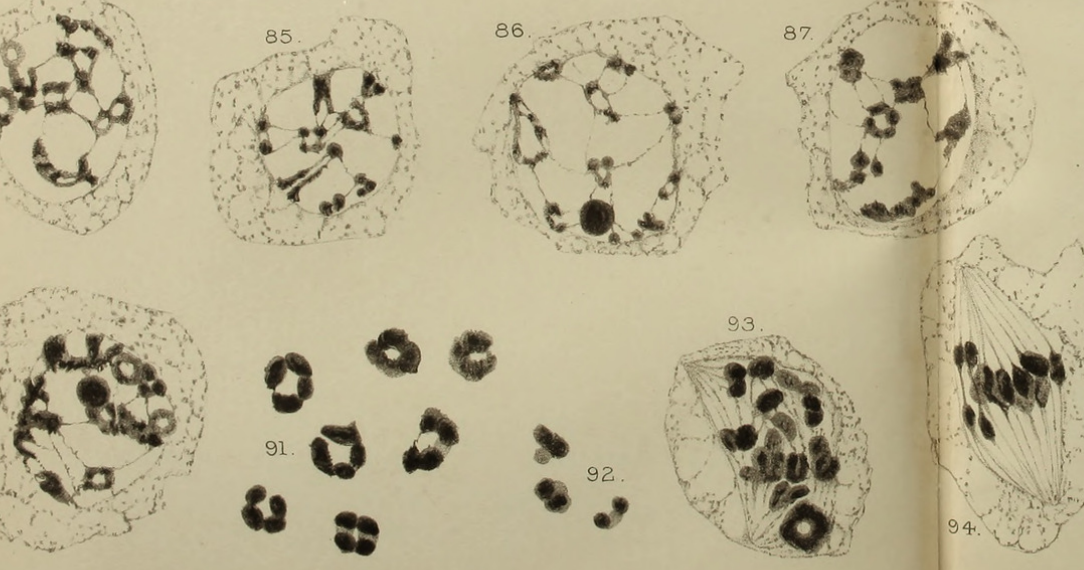

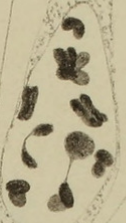
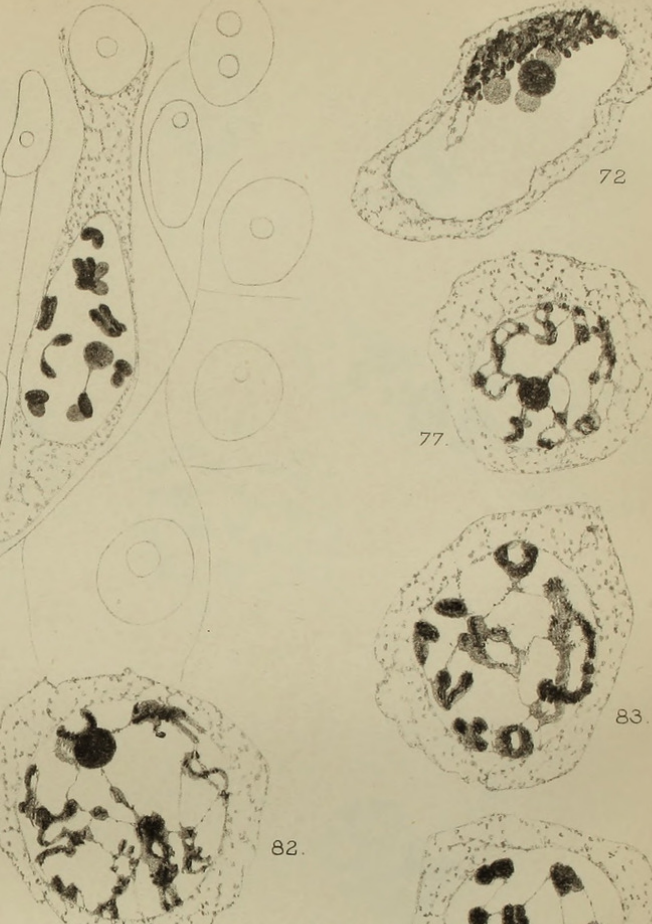

$\int_{0}^{0} 0$
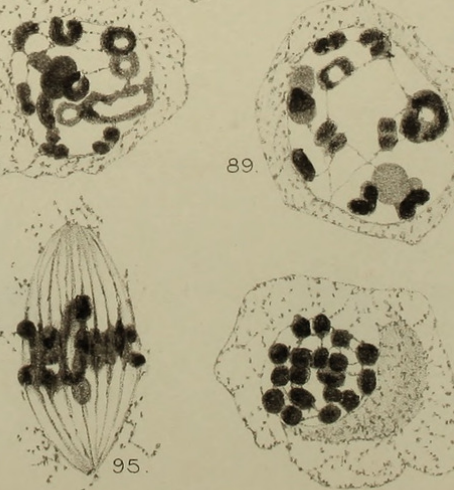
Annals of Botany.
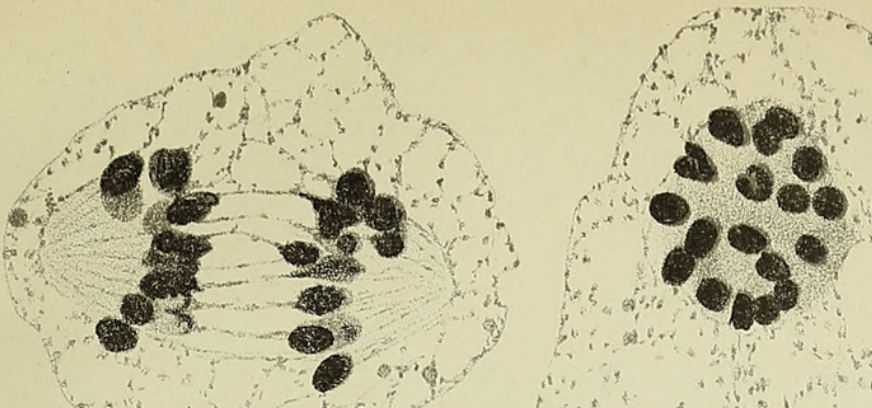

$n$
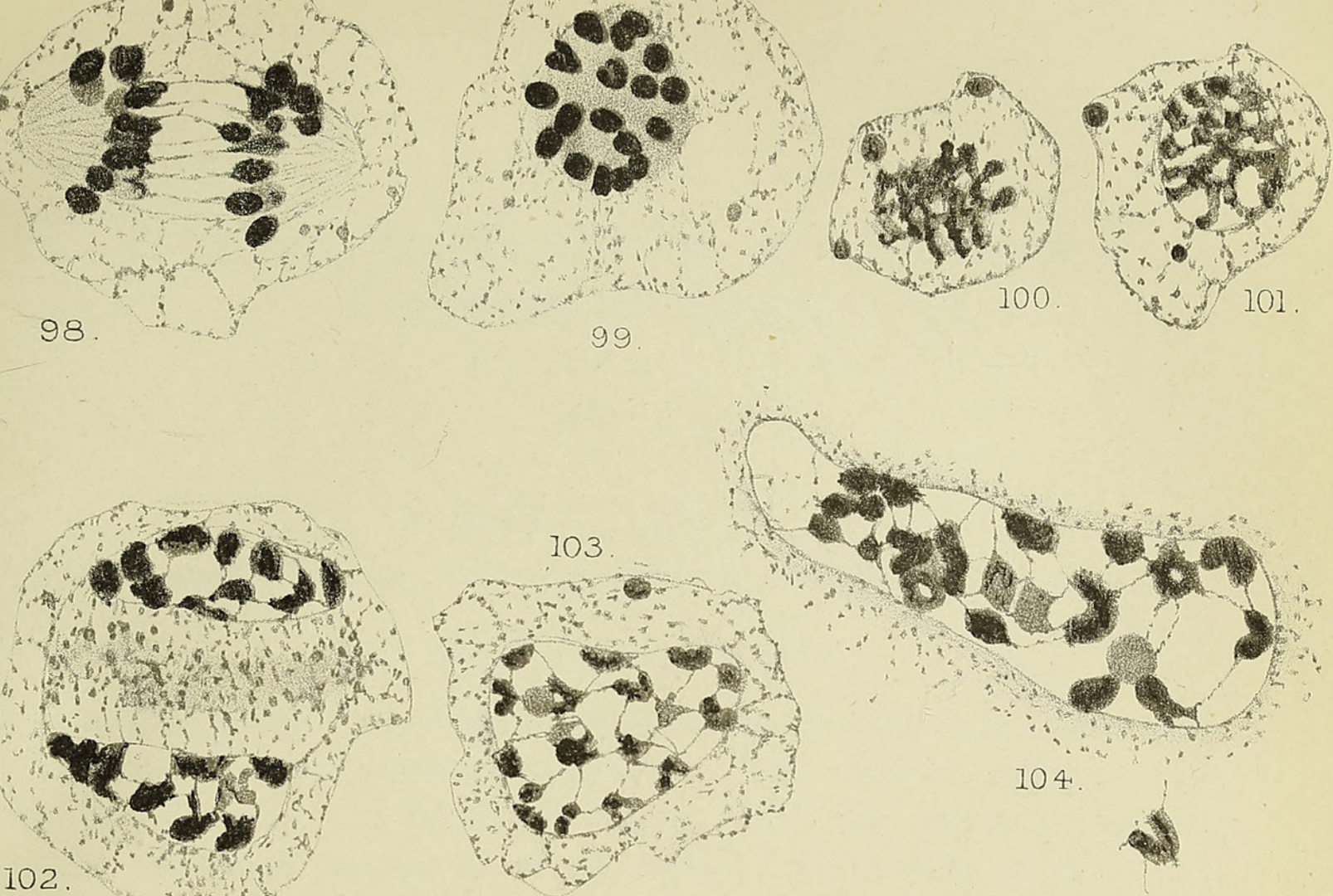

99

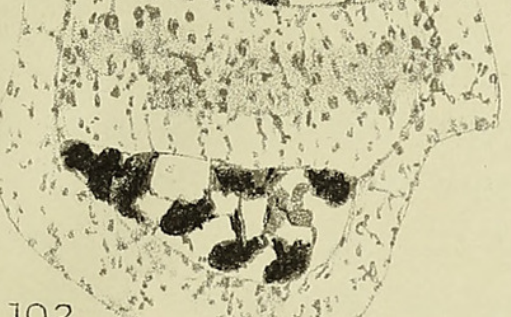

102.
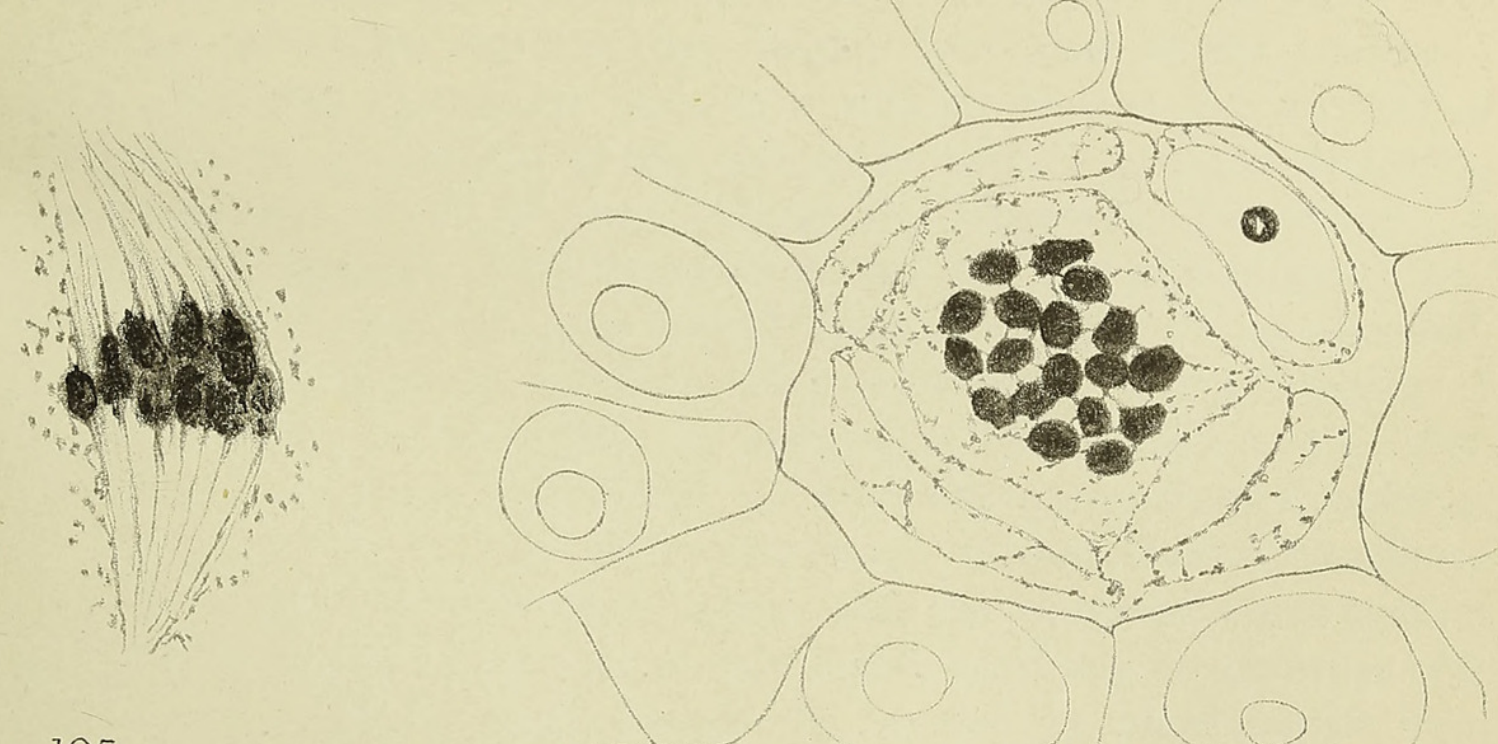

105.

106

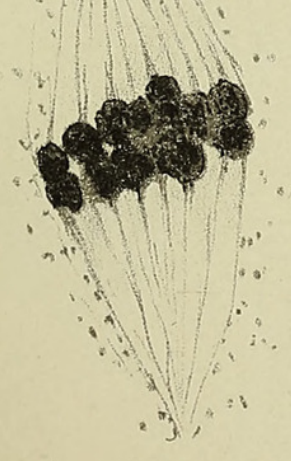

107.
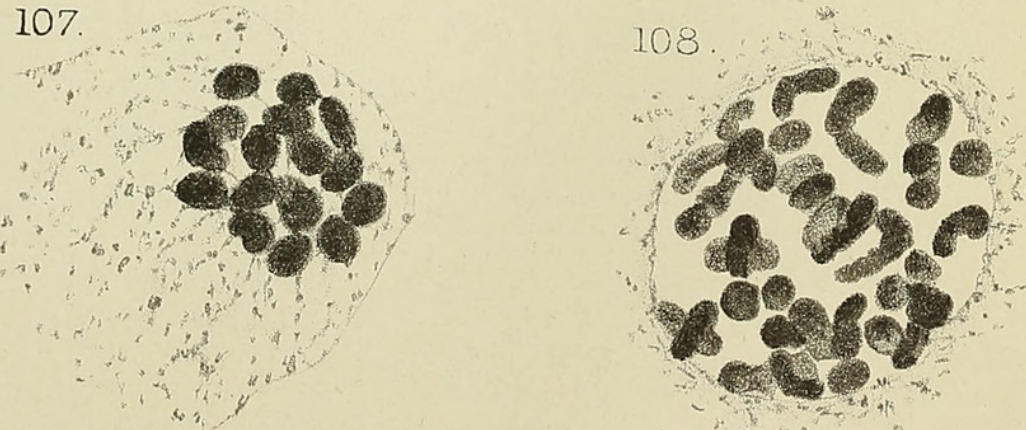


\section{$2 \mathrm{BHL}$ Biodiversity Heritage Library}

Digby, Lettice. 1912. "The cytology of Primula kewensis and of other related Primula hybrids." Annals of botany 26, 357-388.

https://doi.org/10.1093/oxfordjournals.aob.a089395.

View This Item Online: https://www.biodiversitylibrary.org/item/236773

DOI: https://doi.org/10.1093/oxfordjournals.aob.a089395

Permalink: https://www.biodiversitylibrary.org/partpdf/319909

\section{Holding Institution}

Smithsonian Libraries

\section{Sponsored by}

Biodiversity Heritage Library

\section{Copyright \& Reuse}

Copyright Status: Not in copyright. The BHL knows of no copyright restrictions on this item.

This document was created from content at the Biodiversity Heritage Library, the world's largest open access digital library for biodiversity literature and archives. Visit BHL at https://www.biodiversitylibrary.org. 